\title{
Indian hedgehog signaling regulates proliferation and differentiation of chondrocytes and is essential for bone formation
}

\author{
Benoit St-Jacques, ${ }^{1}$ Matthias Hammerschmidt, ${ }^{2}$ and Andrew P. McMahon ${ }^{3}$ \\ Harvard University, Department of Molecular and Cellular Biology, Cambridge, Massachusetts 02138 USA
}

The mechanisms that control cell proliferation and cell differentiation during morphogenesis of the endochondral skeleton of vertebrates are poorly understood. Indian hedgehog (Ihh) signaling from prehypertrophic chondrocytes has been implicated in the control of chondrocyte maturation by way of feedback control of a second secreted factor parathyroid hormone-related peptide (PTHrP) at the articular surfaces. Analysis of an Ihh null mutant suggests a more extensive role for Ihh in skeletal development. Mutants display markedly reduced chondrocyte proliferation, maturation of chondrocytes at inappropriate position, and a failure of osteoblast development in endochondral bones. Together, the results suggest a model in which Thh coordinates diverse aspects of skeletal morphogenesis through PTHrP-dependent and independent processes.

[Key Words: Signaling; Drosophila; cell proliferation; differentiation; chondrocytes; skeletal morphogenesis]

Received May 21, 1999; revised version accepted July 7, 1999.

Development of the vertebrate skeleton is a highly regulated process that takes place by at least two distinct mechanisms: intramembranous and endochondral ossification (Gilbert 1997). In the former, bone forms directly from mesenchymal progenitors, whereas in the latter bone is formed after first generating a cartilaginous model (Hall 1988; Horton 1990; Recker 1992). Membranous bones are restricted to the head and part of the clavicle. In contrast, the axial and appendicular skeletons develop by endochondral ossification.

In the limbs, where extensive growth is required for proximal-distal extension of the long bones, endochondral development begins with the aggregation of undifferentiated mesenchymal cells to form condensations, which by their position, shape, and size already prefigure the future skeletal elements (Hinchcliffe and Johnson 1990). In the core of these condensations, cells differentiate into chondrocytes, which secrete cartilage matrix. At the periphery, cells form a perichondrial sheath that surrounds the cartilage model. Proliferation of chondrocytes and perichondrial cells, as well as deposition of

Present addresses: ${ }^{1}$ Ontogeny, Inc., Cambridge, Massachusetts 02138 USA; Spemann-Laboratories, Max-Plank-Institut für Immunobiologie, Frieburg, Germany.

${ }^{3}$ Corresponding author. new matrix, are responsible for initial growth of these skeletal elements. At a certain stage, which is specific for each element, cells in the center undergo further maturation into hypertrophic chondrocytes, a process characterized by their exit from the cell cycle, enlargement and secretion of a distinct extracellular matrix that becomes progressively calcified (Poole 1991). As a result, immature proliferating chondrocytes become restricted to each end of the skeletal element. These changes are accompanied by direct differentiation of perichondrial cells into osteoblasts, followed in turn by the deposition of a calcified bone matrix, the "bone collar," around the cartilaginous core of the future long bone (Caplan and Pechak 1987). Changes in the composition and properties of the cartilage matrix in the hypertophic zone, allow invasion by capillaries, accompanied by apoptosis of terminally differentiated chondrocytes, degradation of the calcified cartilage matrix, and its replacement by the trabecular bone matrix secreted by invading osteoblasts. The ordered progression of the differentiation program and the columnar arrangement of the chondrocytes result in a stratified organization where zones of proliferation, maturation, hypertrophy, calcification, and bone formation can be recognized, proceeding from the articular ends to the shaft of the bone. Continued proliferation of the less mature chondrocytes at the extremities, their differentiation into hypertrophic chondrocytes, and their 
replacement by trabecular bone near the center results in longitudinal growth of the bone. Continued deposition of cortical bone by the periosteum leads to radial growth. Finally, bone remodeling results from the combined activities of the osteoclasts, bone resorbing cells of hematopoietic origin, and the osteoblasts. Coordinating each of these processes is critical in determining the size, shape, and mechanical properties of the bones.

The molecular mechanisms controlling the chondrogenic and osteogenic program are just starting to be elucidated (for review, Reddi 1994; Erlebacher et al. 1995; Wallis 1996; Rodan and Harada 1997). Several lines of evidence indicate that the signaling factor parathyroid hormone-related peptide (PTHrP) regulates the process of chondrocyte maturation. Targeted inactivation of the genes encoding either PTHrP or its receptor (parathyroid hormone/parathyroid hormone-related peptide receptor, $\mathrm{PTH} / \mathrm{PTHrP}-\mathrm{R}$ ) in the mouse, result in a lethal phenotype, a feature of which is skeletal dysplasia characterized by premature maturation of chondrocytes leading to excessive bone formation at birth (Karaplis et al. 1994; Lanske et al. 1996). Conversely, overexpression of PTHrP in chondrocytes leads to a delay in chondrocyte maturation and bone formation such that mice are born with a completely cartilaginous endochondral skeleton (Weir et al. 1996). In addition, mutations resulting in constitutively active PTH/PTHrP-R in humans cause a rare autosomal dominant disorder, Jansen metaphyseal chondrodysplasia, characterized by widespread growth plate abnormalities including delayed mineralization and distorted columns of chondrocytes (Schipani et al. 1995, 1996). Targeted overexpression of this receptor in mouse chondrocytes reproduces several aspects of the human dysplasia (Schipani et al. 1997). Although PTHrP is expressed at highest levels by the cells of the periarticular perichondrium, at the ends of developing long bones, PTH/PTHrP-R is expressed at low levels throughout the region of immature chondrocytes and at highest levels in mitotically active chondrocytes in the proliferative zone from where postmitotic hypertrophic precursors emerge (Amizuka et al. 1996; Lee et al. 1994, 1995, 1996). Chimeric studies indicate that PTH/PTHrP-R acts in a cell autonomous manner to prevent cells close to the articular ends committing to a hypertrophic fate (Chung et al. 1998). Thus, it has been proposed that PTHrP secreted by cells at the periarticular ends of the developing bone diffuses and acts on chondrocytes expressing PTH/ PTHrP-R to prevent or slow down their progression into postmitotic hypertrophic cells (for review, see Wallis 1996; Kronenberg et al. 1997). PTHrP and its receptor are also present in the periosteum and the main ossification centers (Amizuka et al. 1996; Lee et al. 1994, 1995), where signaling may also regulate vascular invasion and bone formation.

Indian hedgehog (Ihh), which encodes a member of the Hedgehog family of signaling factors, is initially expressed in chondrocytes of the early cartilaginous skeletal elements (Bitgood and McMahon 1995). On maturation, expression becomes progressively restricted to postmitotic prehypertrophic chondrocytes adjacent to the PTH/PTHrP-R-expressing proliferative zones (Bitgood and McMahon 1995; Vortkamp et al. 1996; Iwasaki et al. 1997; Zou et al. 1997). Vortkamp et al. (1996) demonstrated that ectopic expression of $I h h$ in developing chick long bones induces up-regulation of PTHrP expression in the articular perichondrium, leading to delayed differentiation of the chondrocytes, and delayed and abnormal ossification (Vortkamp et al. 1996), a phenotype opposite to that seen in mice homozygous for null mutations in either PTHrP or its receptor (Karaplis et al. 1994; Lanske et al. 1996). Furthermore, addition of Hedgehog protein to limb cultures delayed chondrocyte differentiation but only if PTHrP signaling was intact (Lanske et al. 1996; Vortkamp et al. 1996). These results suggest that Ihh and PTHrP regulate chondrocyte differentiation through the establishment of a negative feedback mechanism (Vortkamp et al. 1996), in which production of Ihh by prehypertrophic chondrocytes induces PTHrP expression, thereby preventing additional chondrocytes from moving down the differentiation pathway. When prehypertrophic chondrocytes fully differentiate they no longer express Ihh. Consequently, the negative feedback mechanism is attenuated and new chondrocytes are allowed to initiate the differentiation process (Vortkamp et al. 1996).

The high levels of Patched, a multipass membrane protein that is both a Hedgehog receptor and transcriptional target of Hedgehog signaling (for review, see Ingham 1998), in perichondrial cells adjacent to the prehypertrophic chondrocytes suggested that Ihh may regulate PTHrP expression indirectly through a perichondrial signaling relay (Vortkamp et al. 1996). Here we report that analysis of an Ihh null mutant supports a role for an Ihh/PTHrP feedback mechanism in the control of chondrocyte maturation. In addition, we present evidence that Ihh also controls chondrocyte proliferation and osteoblast development. Thus, Ihh signaling plays a pivotal role in coordinating several different cellular processes, which are essential for morphogenesis of the vertebrate skeleton.

\section{Results}

Generation of a null allele of Ihh

The Ihh locus was targeted in embryonic stem (ES) cells, replacing the entire first exon of Ihh and $\sim 1 \mathrm{~kb}$ of flanking sequence with a neomycin resistance cassette (Fig. 1A). Properly targeted clones (verified by Southern blot analysis with 5' - and $3^{\prime}$-flanking probes; Fig. 1A; data not shown) were obtained at a frequency of $\sim 1$ in 35 in both the CJ7 (Swiatek and Gridley 1993) and RI (Nagy et al. 1993) ES cell lines. As exon 1 encodes over half of the Ihh-signaling peptide, targeting creates a null allele. Four independently targeted ES cell lines (two CJ7 and two RI) were used to generate chimeras, which transmitted the recombinant allele (Fig. 1B; data not shown). In all cases, heterozygous intercrosses produced homozygous Ihh mutant embryos with identical phenotypes on a random bred (Swiss-Webster), $F_{1}(129 / \mathrm{SV} \mathrm{C} 57 \mathrm{~B} 16 / \mathrm{J})$, or inbred (129/Sv) backgrounds. 


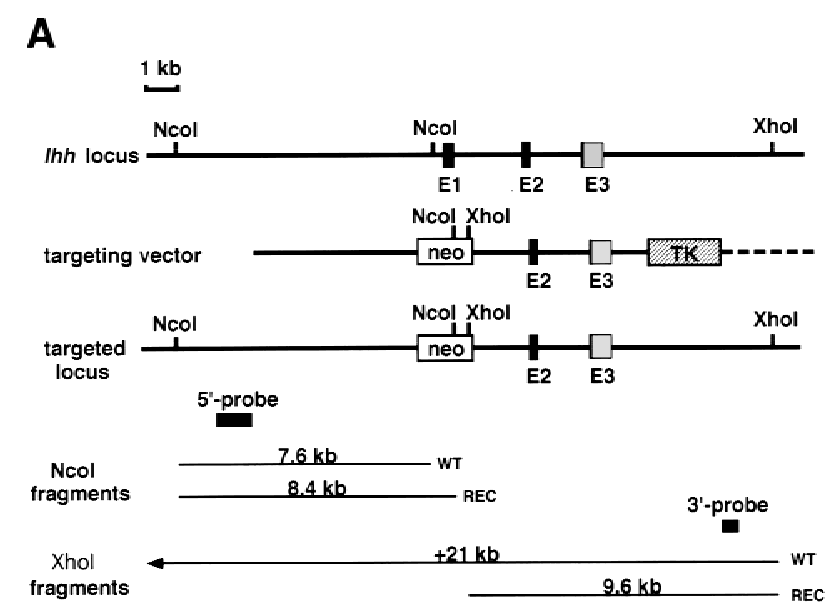

B

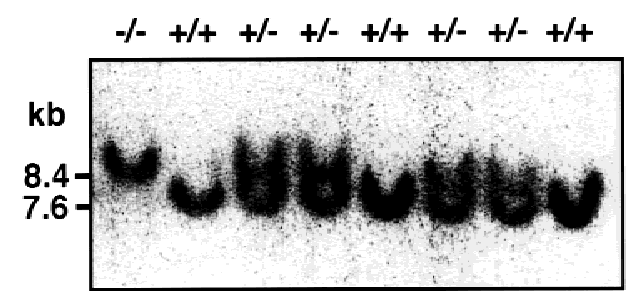

Figure 1. Generation of $I h h$ null mice by gene targeting. $(A)$ Diagram of the Ihh locus, the targeting vector, and the mutant allele. E1, E2, and E3 indicate exons 1 to 3 of the Ihh gene. Black boxes correspond to the sequence encoding the 19-kD signaling peptide. The location of the fragments used as probes in Southern blotting are shown, as well as the sizes of the NcoI and XhoI fragments detected for wild-type and targeted alleles. $(B)$ Southern blot analysis of genomic DNA. DNA from 16.5-dpc embryos was digested with $\mathrm{NcoI}$ and hybridized with the KpnI-HindIII 5'probe shown in $A$. The resulting 7.6- and 8.4-kb bands correspond to the wild-type and mutated alleles, respectively.

Almost half of the $\mathrm{Ihh}^{-/-}$embryos died between 10.5 and 12.5 days postcoitum (dpc) (Table 1). The exact cause of midgestational death is under study but most likely relates to circulatory abnormalities resulting from absence of normal Ihh activity in the yolk sac where it is expressed in the visceral endoderm from as early as 7.5 dpc (Becker et al. 1997; Farrington et al. 1997). Although some lethality occurred in late gestation (Table 1), most of the remaining $\mathrm{Ihh}^{-/-}$embryos developed to term but died at birth, due to respiratory failure. The first overt sign of an embryonic phenotype was an obvious shortening of the forelimbs, visible at $13.5 \mathrm{dpc}$ (Fig. 2A, B). At birth, the mutant animals were invariably shorter than their wild-type littermates, had a foreshortened snout and mandible, a rounded skull, a short tail, and displayed severe dwarfism of the limbs (Fig. 2C, D).

Skeletons were stained with alcian blue and alizarin red to detect cartilage and calcified tissue (hypertrophic cartilage and bone), respectively. Importantly, in the mutant, most of the skeletal elements were present in the right position and in the right number (Fig. 2E,F). Thus, early events in patterning of the skeleton, which precede Ihh expression in condensed chondrocytes, were not significantly affected, as expected. However, later events in skeletogenesis were clearly abnormal, as all appendicular and axial skeletal elements showed dwarfism (Fig. 2E, F). The severe shortening of the ribs prevented breathing and most likely accounts for the early perinatal mortality of $I h h$ mutants. In addition to the reduction in size, most endochondral bones were somewhat misshapen and not all joints formed properly (see below). However, most skeletal elements, which were calcified in the wild-type skeleton, also showed signs of calcification in the mutant skeleton (Fig. 2E, F), indicating that maturation of the chondrocytes in the endochondral skeleton occurred in absence of thh signaling. Finally, development of the intramembranous bones of the skull appeared much less affected (Fig. 2E, F), suggesting a pronounced skeletal defect related to the process of endochondral ossification.

\section{Abnormal long bones development in $\mathrm{Ihh}^{-/-}$limbs}

In view of previous studies (see Introductory section) we focused our analysis on the long bones of the limbs where the phenotype was most severe, concentrating on forelimb development (Fig. 3A-K). At 12.5 dpc, the initial cartilaginous primordia of the mutant forelimbs were not significantly different from that of their wild-type littermates in size, shape, or stage of development (Fig. $3 \mathrm{~A}, \mathrm{~B})$. This confirmed that condensation of mesenchymal cells to form the anlagen of the future bone and their differentiation into chondrocytes was independent of Thh signaling. At $13.5 \mathrm{dpc}$, a small but reproducible difference was apparent in all specimens. Each cartilage element in the mutant was slightly shorter than the corresponding element in the wild-type limb /data not

Table 1. Genotypes of embryos from $\mathrm{Ihh}^{+-}{ }^{--}$intercrosses

\begin{tabular}{lllllllrr}
\hline & \multicolumn{7}{c}{ Developmental stages (dpc) } \\
\cline { 2 - 7 } Genotype & \multicolumn{1}{c}{10.5} & 11.5 & 12.5 & 13.5 & 14.5 & 16.5 & 18.5 & Total \\
\hline$+/+$ & 20 & 6 & 22 & 21 & 21 & 21 & 26 & $137(28.4)$ \\
$+/-$ & 34 & 5 & 51 & 60 & 51 & 49 & 32 & $282(58.4)$ \\
$-/-$ & $14(20.6)$ & $4(26.7)$ & $13(15.1)$ & $11(12)$ & $11(13.3)$ & $4(5.4)$ & $7(10.8)$ & $64(13.2)$ \\
Total & 68 & 15 & 86 & 92 & 83 & 74 & 65 & 483 \\
\hline
\end{tabular}

Percentages are in parentheses. 


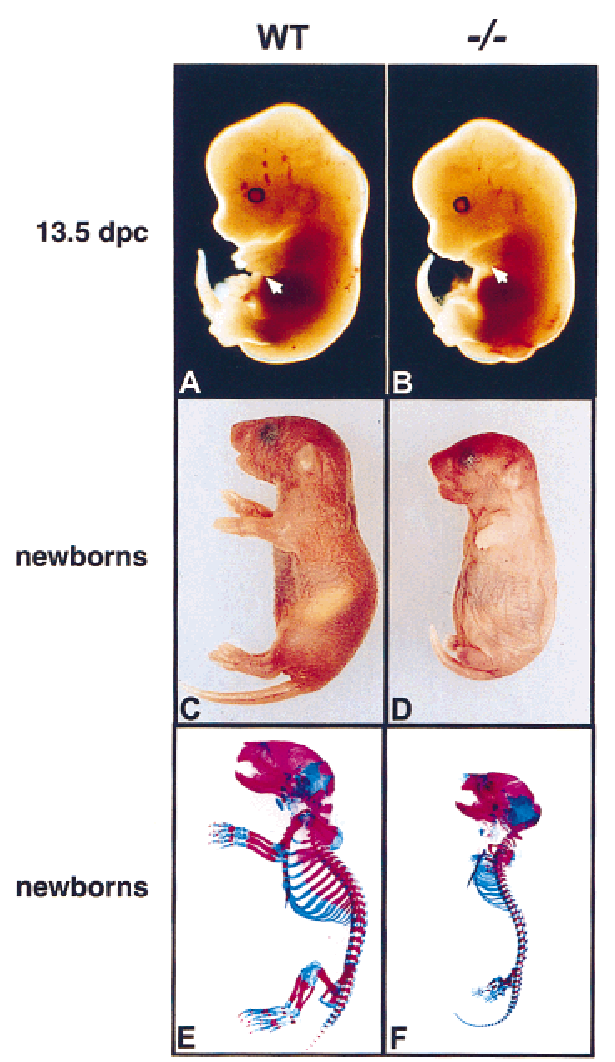

Figure 2. Phenotype of $I h h$ mutant mice. $(A, C, E)$ Wild-type animals $\left(I h h^{+/+}\right) ;(B, D, F)$ mutant animals $\left(\operatorname{Ihh}^{-/-}\right) .(A, B)$ 13.5dpc embryos. The forelimb in the mutant embryo is significantly shorter than in the wildtype (white arrows). $(C, D)$ Gross appearance of newborns. Note the rounded skull, shortened face and tail, and the severe dwarfism of the limbs in the mutant. $(E, F)$ Skeletons of newborns stained with Alcian blue (cartilage) and Alizarin red (calcified tissue). General patterning of the skeleton is normal but all elements of the axial and appendicular skeletons are significantly reduced in size in the mutant.

shown), a difference that became quite obvious by 14.5 dpc (Fig. 3C, D). This difference became progressively more severe (Fig. 3E-H), such that by the time of birth the long bones of the mutants were only one-third the length of those in their wild-type littermates [for humans $1.55 \mathrm{~mm}$ (S.D. $\pm 0.11 \mathrm{~mm}$ ) vs. $4.46 \mathrm{~mm}$ (S.D. \pm 0.18 $\mathrm{mm})$, respectively; $P<0.001$ on Student's $t$-test, $n=10$ ]. Although this failure of bone growth is the most striking feature of the Ihh null phenotype, differentiation is also abnormal. The first signs of calcification in the wild-type humerus were visible at $14.5 \mathrm{dpc}$ as the formation of a bone collar around the cartilage at midshaft (Fig. 3C, I). Extensive calcification was detected in all long bones of wild-type embryos by 15.5 dpc (data not shown). However, it was not until $16.5 \mathrm{dpc}$ that the first signs of calcification were detected in the scapula and humerus of the mutants (Fig. 3F,J) and slightly later in the radius and ulna (data not shown). This initial calcification took the appearance of a single focus of alizarin red staining in the center of the cartilage suggesting that mineralization was occurring in the cartilage and not in association with a bone collar (Fig. 3J). By 18.5 dpc, however, calcification was proportionally more extensive in the mutant bones than in the wild-type, extending closer to the articular surfaces reminiscent of mutants in PTHrP or its receptor (arrowheads in Fig. 3K). This was also evident in other skeletal elements including the sternum, the vertebrae, and the cartilaginous synchondroses of the base of the skull (data not shown). We also observed a failure of digit segmentation, which initiates in wild-type embryos around $14.5 \mathrm{dpc}$ (Fig. 3C, D). However, even at the

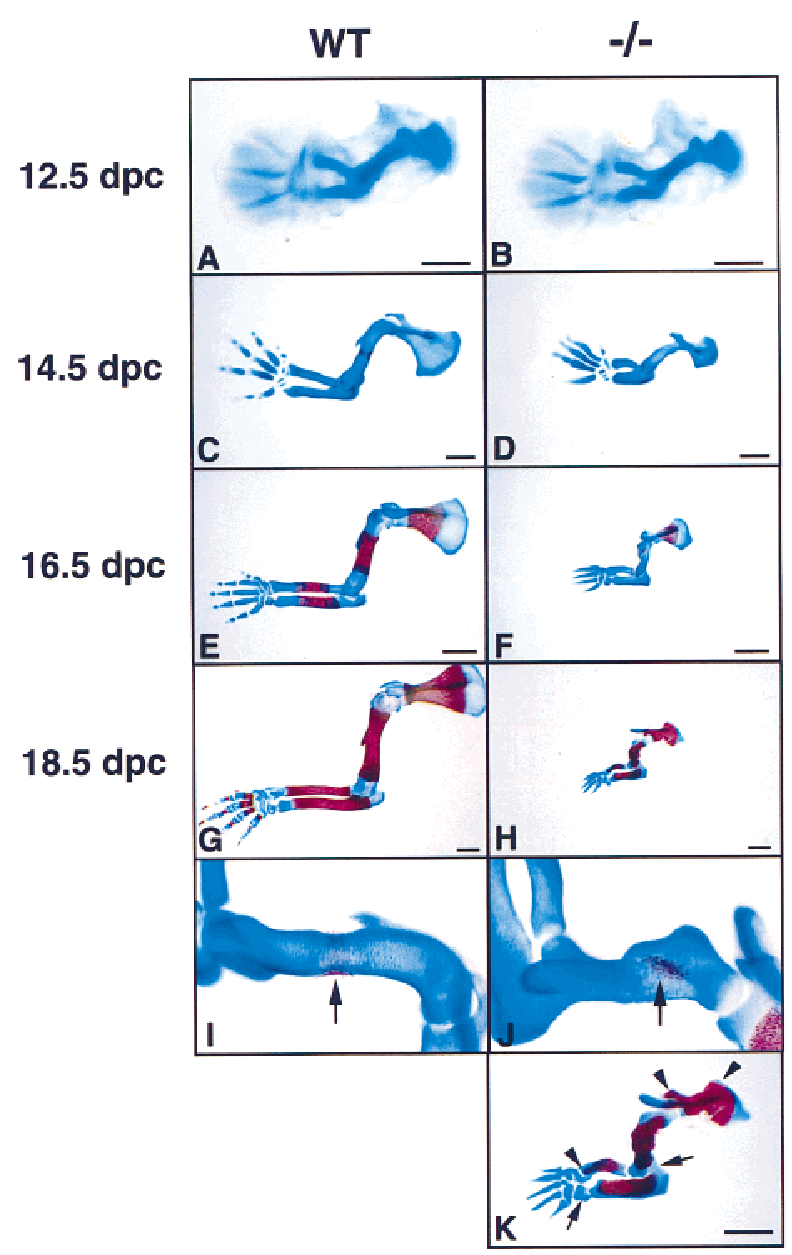

Figure 3. Development of the forelimb skeleton. $(A, C, E, G, I)$ Wild-type forelimbs; $(B, D, F, H, I, K) \mathrm{Ihh}^{-/-}$forelimbs. In $A$ and $B$ forelimbs were stained with Alcian blue. In $C-K$ forelimbs were stained with Alcian blue and Alizarin red. $(A, B)$ 12.5-dpc limbs. Note that the initial cartilage elements form normally in the mutant. $(C, D)$ 14.5-dpc limbs. $(E, F)$ 16.5-dpc limbs. $(G, H)$ 18.5dpc limbs. An obvious difference in length of the long bones visible at 14.5 -dpc becomes progressively more severe, indicating a failure of the growth process in the mutant. (I) Higher magnification of the wild-type humerus shown in $C$. Arrow indicates formation of a bone collar. (J) Higher magnification of the $I h h^{-/-}$humerus shown in F. Arrow indicates calcification in the center of the cartilage only. (K) 18.5-dpc $\mathrm{Ihh}^{-1-}$ limb at higher magnification. Arrowheads indicate areas of ectopic calcification. Arrows indicate incomplete joint formation. $(A-D)$ Bar $0.5 \mathrm{~mm} ;(E-H, K)$ bar $1 \mathrm{~mm}$. 
latest stage, the mutant digits remained unsegmented and uncalcified (Fig. 3K). Furthermore, the humerus and ulna, as well as some of the wrist bones, remained partly fused (arrows in Fig. 3K).

\section{Reduced chondrocyte proliferation in $\mathrm{Ihh}^{-/-}$cartilage}

Before chondrocyte hypertrophy, growth within the cartilage element is largely dependent on proliferation of chondrocytes. To address proliferation in Ihh-mutant limbs, we measured bromodeoxyuridine (BrdU) incorporation into proliferating chondrocytes between 12.5 and $14.5 \mathrm{dpc}$. As shown in Figure 4, A and B, there was not only a marked reduction in the percentage of BrdU-positive nuclei in the proliferative zone of the mutant but also a dramatic reduction in the length of the proliferative zone. The proportion of BrdU-positive nuclei in the humerus of the mutant was approximately one-half that of the wild-type littermate from as early as $12.5 \mathrm{dpc}$ (Fig. 4C). Ihh is first expressed in chondrocytes of the humerus at $11.5 \mathrm{dpc}$ (Bitgood and McMahon 1995). Thus, Ihh signaling is required to maintain the high rate of chondrocyte proliferation observed in the rapidly growing long bones of the early mammalian skeleton.

\section{Proliferating chondrocytes are likely direct targets of Ihh signaling}

Ihh signaling at early stages of chondrogenesis has not been addressed rigorously in earlier studies. The failure of normal proliferation in the mutant cartilage indicated that immature chondrocytes might be a target of Ihh signaling. Therefore, we compared the expression patterns of $I h h$, and its receptor, and transcriptional target Patched-1 (Ptc-1), in the developing humerus of wildtype and Ihh mutant embryos. In wild-type limbs, Ihh transcripts were detected at $12.5 \mathrm{dpc}$ in chondrocytes in the center of the cartilage condensation (Fig. 4D). Ptc-1 was detected in a much broader domain, which included almost all the chondrocytes as well as surrounding mesenchyme outside of the condensation (Fig. 4E). No expression of Ihh or Ptc-1 was detected in the mutant skeleton at any stage, confirming that Ihh signaling is required to induce high levels of Ptc-1 expression (Fig. 4F, G). Expression of the transcription factor Gli-1, a transcriptional target and effector of Hedgehog signaling, was found to be generally similar to that of Ptc-1, and was similarly down-regulated in the mutant (data not shown). At $13.5 \mathrm{dpc}$, Ihh expression in the wild-type humerus was down-regulated in the more mature central cells that are undergoing hypertrophy (Fig. 4H). Ptc-1 expression could be detected in proliferating chondrocytes adjacent to those expressing Ihh (arrow in Fig. 4I). In addition, a very strong signal was detected in the perichondrium/periosteum at this stage (Fig. 4I). At later stages, Ihh expression was restricted to the prehypertrophic chondrocytes (Fig. 4J). Ptc-1 expression was still detected in proliferating chondrocytes adjacent to the Ihh expression domain (arrow in Fig. 4K), but its expression

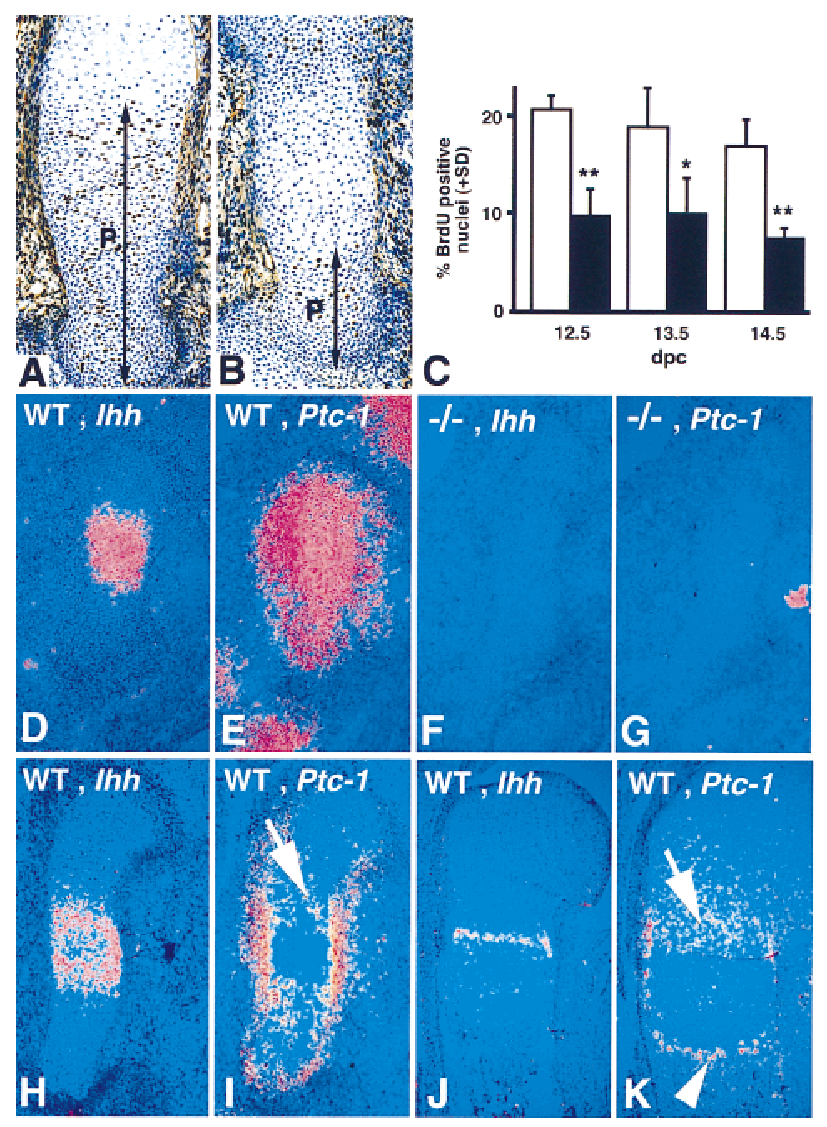

Figure 4. Reduced chondrocyte proliferation and absence of Ihh and Ptc-1 expression in embryonic long bones in the Ihh mutant. $(A, B)$ BrdU labeling in the humerus of wild-type $(A)$ and $I h h^{-1-}(B)$ embryos at $14.5 \mathrm{dpc}$. BrdU-positive nuclei are stained black. All nuclei are counter stained with toluidine blue. The black bar annotated P indicates the extent of the zone of proliferation. $(C) \mathrm{BrdU}$ incorporation calculated as percentage of BrdU-positive nuclei in the proliferation zone at different developmental stages. Bars represent means + S.D.. (Open bars) wildtype, (solid bars) Ihh ${ }^{-1-}$. (*) $\left.P<0.01 ;{ }^{* *}\right) P<0.005$ (Student's $t$-test). $(D-K) 35-\mathrm{S}$ in situ hybridization for Ihh and Ptc-1 on longitudinal sections through wild-type and $I h h^{-/-}$humerus at different stages of development. $(D, F, H, J)$ Ihh expression. (E, $G$, $I, K)$ Ptc-1 expression. $(D, E)$ Wild-type humerus at 12.5 -dpc. Ihh is expressed by the chondrocytes in the center of the cartilage $(D)$, Ptc-1 is expressed in a much broader domain $(E) .(F, G)$ Ihh $-/-$ humerus at $12.5 \mathrm{dpc}$. Note the absence of Ihh $(F)$ and Ptc-1 $(G)$ expression in the mutant cartilage (the hybridization signal seen in $G$ is not associated with the cartilage and probably represents Ptc-1 expression in the developing nerves). (H,I) Wildtype humerus at $13.5 \mathrm{dpc}$. Although $\mathrm{Ihh}$ expression is starting to get down-regulated in the more mature chondrocytes in the center of the cartilage $(H), P t c-1$ is expressed at a high level in the perichondrium and at a lower level in proliferating chondrocytes (arrow in $I) .(J, K)$ Wild-type humerus at $18.5 \mathrm{dpc}$. Ihh expression $(J)$ is restricted to the prehypertrophic chondrocytes; Ptc-1 expression $(K)$ is detected in the proliferating chondrocytes (arrow) and in a new domain at the chondro-osseus junction (arrowhead).

in the perichondrium/periosteum was restricted to the area surrounding the Ihh-expressing cells. A new domain 
of Ptc-1 expression was also detected in the primary spongiosa were osteogenic cells replaced the hypertrophic cartilage (arrowhead in Fig. 4K). Thus, at all developmental stages examined, proliferating chondrocytes expressed the receptor Ptc-1 and therefore, are likely to be direct targets of Ihh signaling. Ptc-1 expression, in regions of osteogenesis, also suggests a possible link with bone formation. No significant expression of the closely related molecule Ptc-2 was detected in the developing long bones (data not shown).

\section{Chondrocyte maturation and bone formation are abnormal in Ihh mutants}

Having demonstrated that Ihh is essential for normal levels of chondrocyte proliferation, we next examined the differentiation process. At 12.5 dpc both wild-type and mutant cartilages were made up of a relatively uniform population of tightly packed chondrocytes (data not shown). At $13.5 \mathrm{dpc}$, cells in the center of the wild-type humerus initiated the process of hypertrophic differentiation (arrow in Fig. 5A, and Fig. 5C). At this stage in the mutant, typical hypertrophic chondrocytes were ab- sent (Fig. 5B), although many central chondrocytes appeared vacuolated (Fig. 5D). At $14.5 \mathrm{dpc}$, the hypertrophic zone had greatly enlarged in the wild-type humerus and proliferating chondrocytes displayed a typical columnar organization (Fig. 5E, G). In addition, vascular invasion of the perichondrium had taken place with the concomitant appearance of a cortical bone collar (arrow in Fig. 5E). Although some hypertrophic cells were present in the center of the mutant humerus (Fig. 5F), these were not as large or as well organized (Fig. $6 \mathrm{H}$ ), and were still flanked laterally by less mature chondrocytes with no sign of vascularization or cortical bone formation (arrow in Fig. 5F). Indeed, whereas wild-type embryos formed extensive cortical bone by $18.5 \mathrm{dpc}$, no formation of cortical bone could be seen histologically in the mutant humerus, even in areas where vascular invasion of the perichondrium had taken place (Fig. 5M, N). Furthermore, although replacement of the terminally differentiated hypertophic cells by invading osteoblasts in the shaft of the wild-type humerus resulted in formation of extensive trabecular bone in the primary spongiosa (Fig. 5I), no histologically identifiable bone was present in the Ihh mutants (Fig. 5J, L). However, in the most advanced

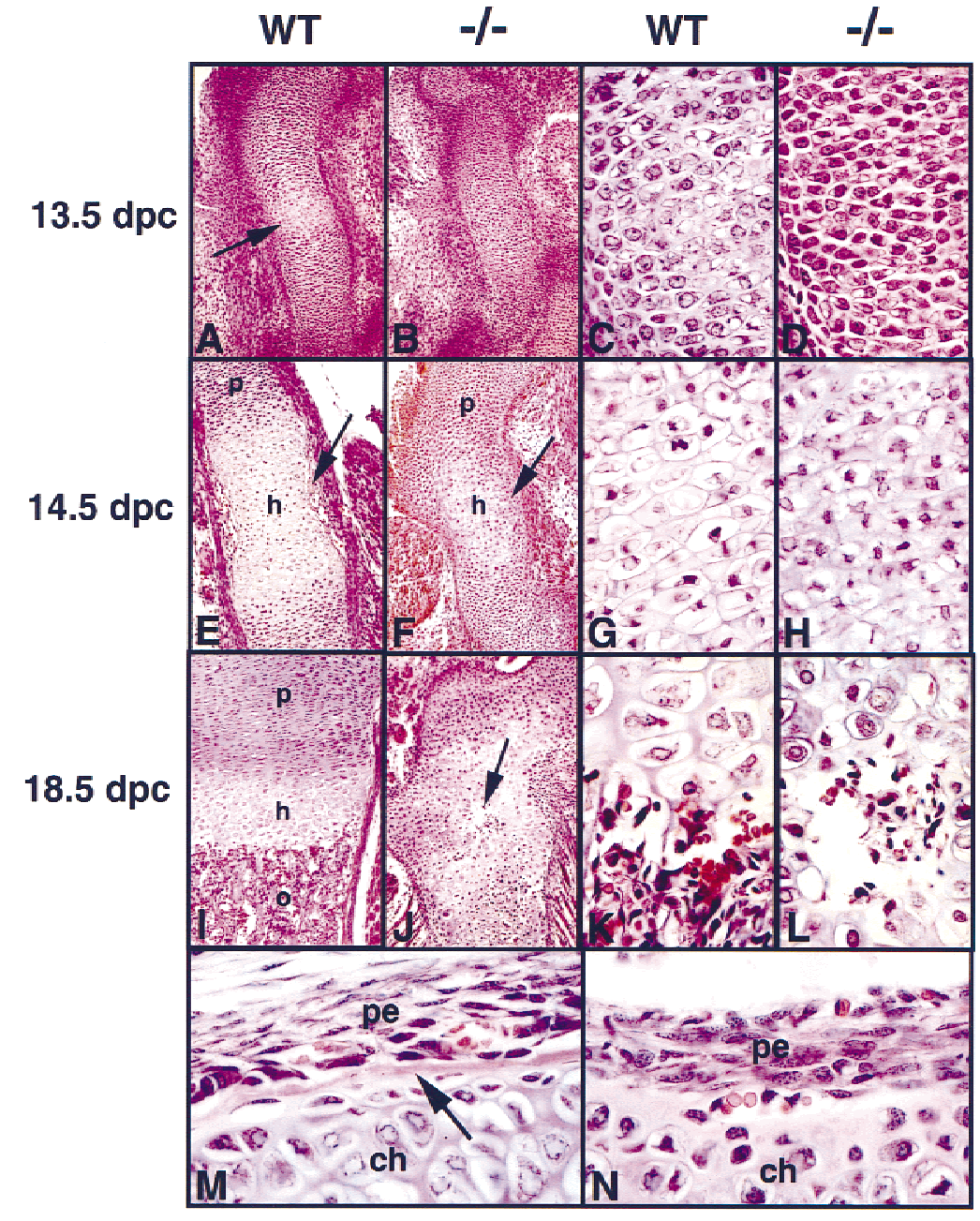

Figure 5. Histological analysis of endochondral ossification in the Ihh mutant. $(A, C, E, G, I, K, M)$ Hematoxylin/eosin-stained longitudinal sections through wild-type humerus. $(B, D, F, H, I, L, N)$ Sections through $I h h^{-1-}$ humerus. In all the panels except $M$ and $N$, proximal is at the top, distal at the bottom. $(A, B) 13.5 \mathrm{dpc}$. The arrow in $A$ points to chondrocytes undergoing hypertrophy in the wildtype humerus. $(C, D)$ Higher magnification of chondrocytes in the center of the bones shown in $A$ and $B$. $(E, F) 14.5 \mathrm{dpc}$. The arrow in $E$ indicates newly formed cortical bone in the wild-type humerus. The arrow in $F$ indicates less mature chondrocytes surrounding the population of hypertrophic cells. $(G, H)$ Higher magnification of chondrocytes in the center of the bones shown in $E$ and $F$. $(I, J) 18.5 \mathrm{dpc}$. The arrow in $J$ indicates a newly formed site of vascular invasion and degradation of the cartilage. $(K, L)$ Higher magnification of cells at the chondro-osseous junction or the newly formed site of vascular invasion shown in $I$ and $I$, respectively. $(M)$ Longitudinal section through a wild-type humerus at 18.5 dpc showing the periosteum and the newly formed cortical bone (arrow) adjacent to the zone of hypertrophic chondrocytes. $(N)$ Section through a Ihh ${ }^{-/-}$ humerus at $18.5 \mathrm{dpc}$ showing the abnormal histology of the perichondrium and the absence of cortical bone formation even in vascularized areas. (ch) chondrocytes; (h) zone of hypertrophic chondrocytes; (o) zone of ossification; (p) zone of proliferating chondrocytes; (pe) perichondrium/periosteum. 
cases, areas of vascular invasion and degradation of the cartilage matrix were visible (arrow in Fig. 5J). Erythrocytes, and some cells with a more fibroblastic appearance like those found at the normal chondro-osseus junction, were present (Fig. 5L), as well as a few large multinucleated cells, possibly osteoclasts (data not shown). Chondrocytes never displayed a clear stacked columnar organization and the area of hypertrophic cells extended to within 20 cell diameters of the articular surface, whereas in wild-type bones hypertrophic cells remained many hundreds of cell diameters from this end. Thus, the extensive alizarin red staining visible in newborn $\mathrm{Ihh}^{-/-}$skeletons resulted from the presence of a calcified cartilage matrix secreted by terminally differentiated hypertrophic chondrocytes, and did not indicate the presence of true bone matrix. In summary, the long bones of the Ihh mutants underwent a delayed and disorganized differentiation. Hypertrophic chondrocytes appeared late but subsequently chondrocyte maturation extended into regions where chondrocytes normally remain undifferentiated. Finally, bone formation was absent. Some elements of the axial skeleton (vertebrae and sternum) presented similar histological findings (data not shown), but the ribs did not show excessive calcification.

To address chondrocyte maturation at the molecular level, we performed a series of section in situ hybridizations to compare expression of collagen type X (Col10), a marker of hypertrophic chondrocytes (Linsenmayer et al. 1991; Apte et al. 1992; Elima et al. 1993) and collagen type II (Col2), which is expressed by less mature chondrocytes. At 12.5 and $13.5 \mathrm{dpc}$, chondrocytes expressed Col2 in both the wild type and the mutant (data not shown). Unexpectedly, at $12.5 \mathrm{dpc}$, we already detected Col10 expression in the center of some wild-type humeri although histologically identifiable hypertrophic cells were not visible (Fig. 6A). No Col10 expression was observed in the mutants (Fig. 6B). At $13.5 \mathrm{dpc}$, robust Col10 expression was found in the wild type in the hypertrophic region, but only patchy Col10 expression was seen in the mutant (Fig. 6C, D). In the wildtype, as cells matured into hypertrophic chondrocytes they abruptly switched from expressing type II to type X collagen such that by $14.5 \mathrm{dpc}$, and at all later stages, there was only a slight overlap in the domains of Col2 and Col10 expression (Fig. 6E, F). In contrast, there was still an overlap between expression of Col2 and Col10 in the mutant (Fig. 6G,H). Thus, it appeared that many chondrocytes were in a transition state, not having down-regulated Col2-expression yet but already expressing high levels of Col10. At $16.5 \mathrm{dpc}$, the hypertrophic cells in the core of the mutant cartilage had matured to a state at which they no longer expressed Col2 (Fig. 6I,J). Note that these mature hypertrophic chondrocytes were still surrounded by a population of less differentiated cells expressing only Col2 (Fig. 6I, J). Finally, at 18.5 dpc, Col2-expressing chondrocytes still surrounded Col10 expression in the mutant, but surprisingly cells in the center of the humerus no longer expressed Col10, although most of these cells still had the appearance of hypertrophic chondrocytes (Fig. 6K, L). These results confirm that chondrocyte
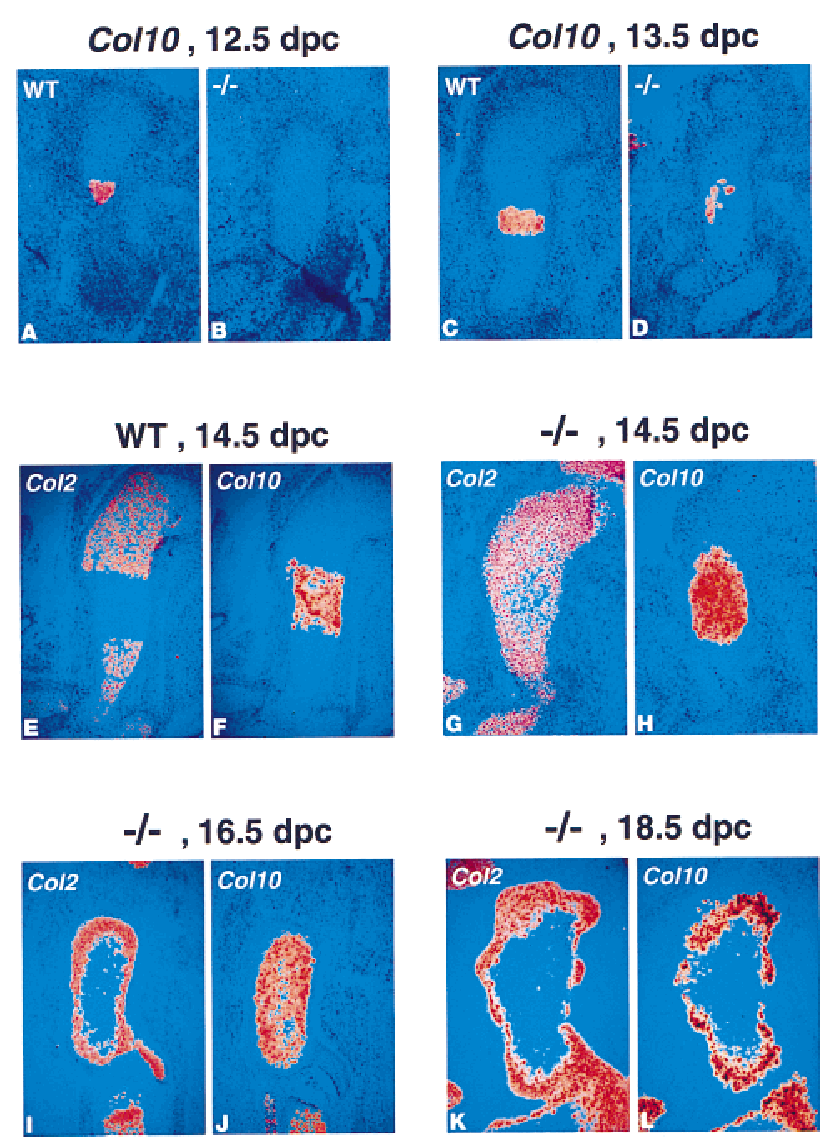

Figure 6. Abnormal patterns of expression of collagen type II and type $\mathrm{X}$, indicate a delay in maturation of the chondrocytes in the $I h^{-/-}$long bones. $(A-L) 35-S$ in situ hybridization for collagen type II (Col2) and type X (Col10) on longitudinal sections through wild-type and $I h^{-/-}$long bones at different stages of development. $(A, B)$ Col10 expression in wild-type $(A)$ and $I h h^{-/-}(B)$ humerus at $12.5 \mathrm{dpc}$. No Col10 expression was detected at this stage in the mutant. $(C, D)$ Col10 expression in wild-type $(C)$ and $I h h^{-1-}(D)$ humerus at $13.5 \mathrm{dpc}$. Only patchy Col10 expression was visible in the mutant. $(E, F)$ Col2 $(E)$ and Col10 (F) expression in wild-type humerus at $14.5 \mathrm{dpc}$. The domains of expression of Col2 (less mature chondrocytes) and Col10 (hypertrophic chondrocytes) are almost nonoverlapping at this stage. $(G, H) \operatorname{Col}(G)$ and $\operatorname{Col10}(H)$ expression in $I^{-1-}$ humerus at $14.5 \mathrm{dpc}$. In the mutant there is still a very broad overlap in Col2 and Col10 expressions at this stage. $(I, J)$ Col2 $(I)$ and Col10 (J) expression in Ihh ${ }^{-/-}$fibula at $16.5 \mathrm{dpc}$. At this stage, the more mature chondrocytes in the center of the cartilage express only Col10. A less mature population expressing only Col2 surrounds these cells. $(K, L)$ Col2 $(K)$ and Col10 $(L)$ expression in $\mathrm{Ihh}^{-/-}$humerus at $18.5 \mathrm{dpc}$.

differentiation was initially delayed, but when it occurred, hypertrophic cells occupied abnormal positions close to the articular surface.

The abnormal location of hypertrophic chondrocytes close to the articular surface is reminiscent of the phenotype in PTHrP and PTH/PTHrP-R mutants (Karaplis et al. 1994; Lanske et al. 1996; Chung et al. 1998). In situ hybridization studies on the forelimb at $14.5 \mathrm{dpc}$ revealed that although the $P T H / P T H r P-R$ was expressed in 
immature chondrocytes in Ihh mutants, the normal periarticular expression of PTHrP was absent (Fig. 7A-D). Thus, in agreement with earlier studies in the chick (Vortkamp et al. 1996), Ihh is required to maintain PTHrP signaling and thereby regulate chondrocyte maturation.

\section{Absence of mature osteoblasts in the $\mathrm{Ihh}^{-1-}$ long bones}

To address the failure of bone formation, we examined the expression of three genes associated with osteoblast development. Osf-2/Cbfa1, a transcriptional activator of osteoblast differentiation, was first described as being expressed in early mesenchymal condensations and later
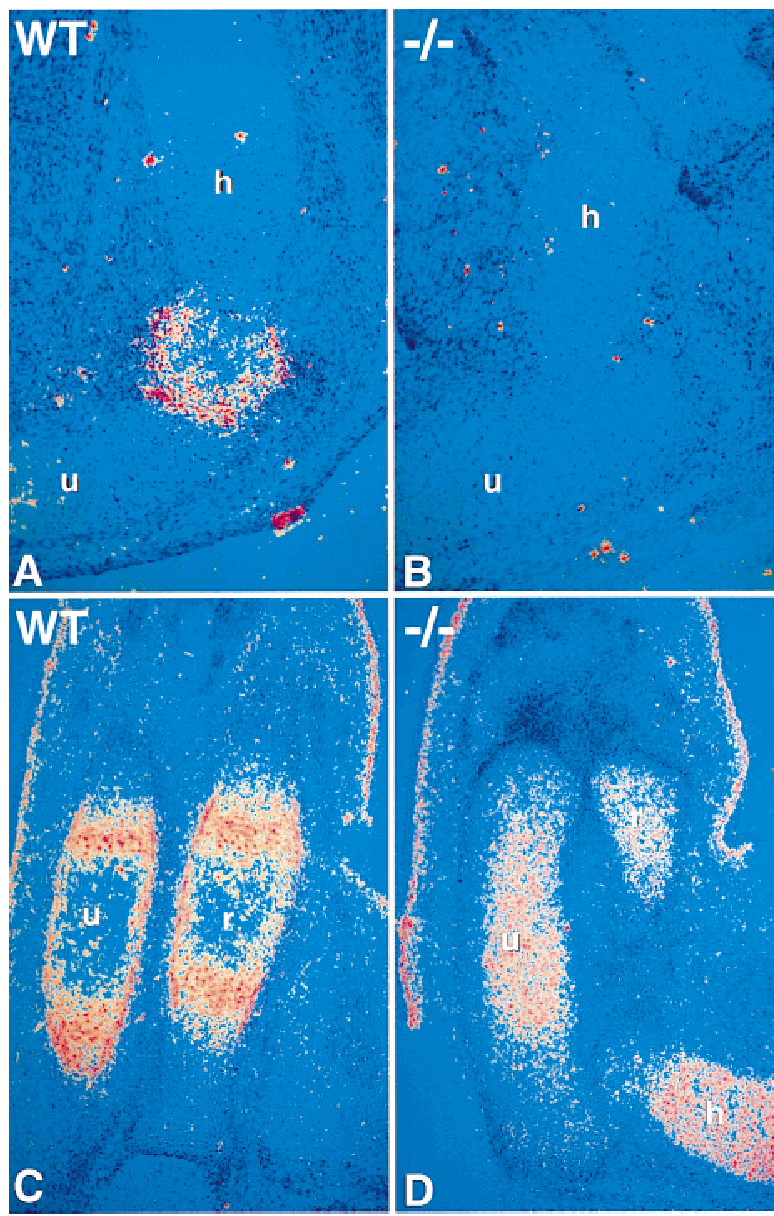

Figure 7. Absence of $P T H r P$ expression in the $\mathrm{Ihh}^{-/-}$mutant. $(A-D) 35 \mathrm{~S}$ in situ hybridization for PTHrP and PTHrP-R on longitudinal sections through wild-type and $I h h^{-1-}$ forelimb bones at 14.5 dpc. $(A, B)$ PTHrP expression in articular perichondrium of wild-type $(A)$ and $I h h^{-/-}(B)$ humerus. No PTHrP expression is detected in the mutant. $(C, D)$ PTHrP-R expression in wildtype $(C)$ and $I h h^{-1-}(D)$ radius and ulna. Note that in the wildtype, $P T H r P-R$ expression is detected in maturing chondrocytes and in the perichondrium/periosteum. There is PTHrP-R expression in the mutant chondrocytes but not in the perichondrium. (h) Humerus; (u) ulna; (r) radius. being restricted to sites of differentiation of preosteoblasts and osteoblasts (Ducy et al. 1997; Otto et al. 1997). Mutants lacking Osf-2/Cbfa1 fail to undergo normal chondrocyte maturation and lack osteoblasts (Komori et al. 1997; Otto et al. 1997). We found that Osf-2/Cbfa1 was normally expressed at high levels in the perichondrial/periosteal region where cortical bone forms (arrow in Fig. 8A) and at low levels in differentiated chondrocytes throughout early development (arrowhead in Fig. 8A). At later stages Osf-2/Cbfa1 was expressed at high levels in the osteogenic areas, the periosteum, and the trabecular bone, and still at low levels in the chondrocytes (Fig. 8C). Conversely, in the mutant expression was restricted to chondrocytes (arrowhead in Fig. 8B,D) but was completely absent from the perichondrial/periosteal tissue (Fig. 8B,D). In wild-type bones, Bmp3 expression was restricted to tissues where preosteoblast and osteoblast differentiation took place (Fig. 8G; see also Vukicevic et al. 1994; Takahashi and Ikeda 1996), the perichondrium/periosteum from $13.5 \mathrm{dpc}$ (Fig. 8E; data not shown), then in areas of trabecular and cortical bone formation at later stages. No Bmp3 expression was detected in the perichondrial/periosteal region of $I h h$ null mutants at any stage (Fig. $8 \mathrm{~F}, \mathrm{H}$ ). However, some late expression was visible in the core of the mutant humerus (Fig. 8H). Finally, the perichondrial/periosteal domain of PTH/PTHrP-R expression was also absent while chondrocyte expression was maintained (Fig. 7C, D, and Fig. 8I, J). The absence of all three markers indicates that Ihh signaling is essential for development of the osteogenic program that leads to cortical bone formation. This conclusion was confirmed and extended by examining the expression of osteocalcin, currently considered the most specific marker of mature osteoblasts (see Aubin and Liu 1996). Although osteocalcin expression was detected in long bones of wild-type embryos (Fig. 8K), no osteocalcin expression could be detected in any endochondral bone in the mutant appendicular or axial skeleton (Fig. 8L; data not shown). In contrast, abundant osteocalcin expression, indicating the presence of mature osteoblasts, was observed in mutant bones formed entirely or partially by intramembranous ossification such as the flat bones of the skull, the mandible, and the clavicle (Fig. 8M; data not shown). Thus, the absence of Ihh signaling affects osteoblast development only in the endochondral skeleton, where mature osteoblasts are completely absent at birth.

\section{Discussion}

We have shown that Ihh mutants display (1) markedly reduced chondrocyte proliferation; (2) initially delayed, then abnormal chondrocyte maturation; and (3) absence of mature osteoblasts. Our analyses indicate that Ihh signaling plays multiple regulatory roles in endochondral bone formation, some of which support existing models of Ihh function, whereas others require a reappraisal of Ihh action. Together, our results demonstrate that Ihh signaling plays a pivotal role in coordinating diverse aspects of skeletal morphogenesis. 


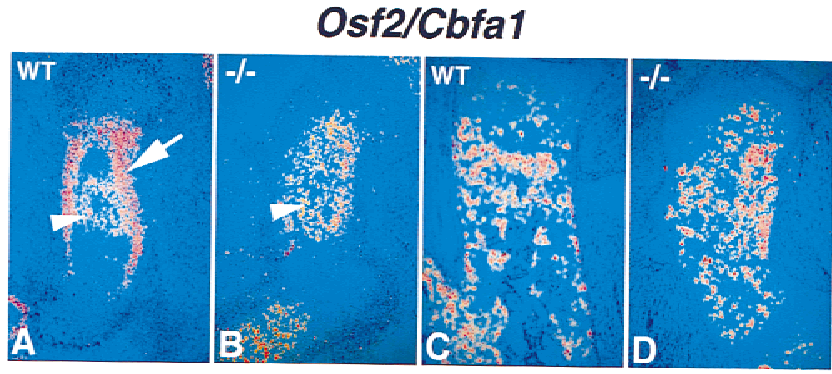

Figure 8. Absence of endochondral bone formation before birth in the Ihh ${ }^{-1-}$ mutant. $(A-L) 35-S$ in situ hybridization for perichondrial markers on longitudinal sections through wild-type and $I h h$ -I- humerus at different stages of development. $(A, C, E, G, I, K)$ Wild-type bones. $(B, D, F, H, I, L$, M) Ihh ${ }^{-/-}$bones. $(A-D)$ Osf-2/Cbfa1 expression. (A) Wild-type at $13.5 \mathrm{dpc}$. Expression is detected in the perichondrium (arrow) and some mature chondrocytes (arrowhead). (B) Ihh ${ }^{-1-}$ at $14.5 \mathrm{dpc}$. Osf-2/Cbfa1 expression is detected only in the more mature chondrocytes at the center of the humerus (arrowhead). $(C, D) 18.5$ dpc. $(E-H) B m p 3$ expression. $(E, F) 14.5$ dpc. $(G, H) 18.5$ dpc. $(I, J)$ PTHrP-R expression at $18.5 \mathrm{dpc}$. Arrow in $I$ indicates expression in the periosteum. Arrowhead in $I$ and $J$ indicates expression in chondrocytes. $(K-$ M) osteocalcin expression. $(K, L) 18.5 \mathrm{dpc}$. (M) Coronal section through parietal bone of the skull in a mutant embryo at $18.5 \mathrm{dpc}$ showing osteocalcin expression in the intramembranous bone.
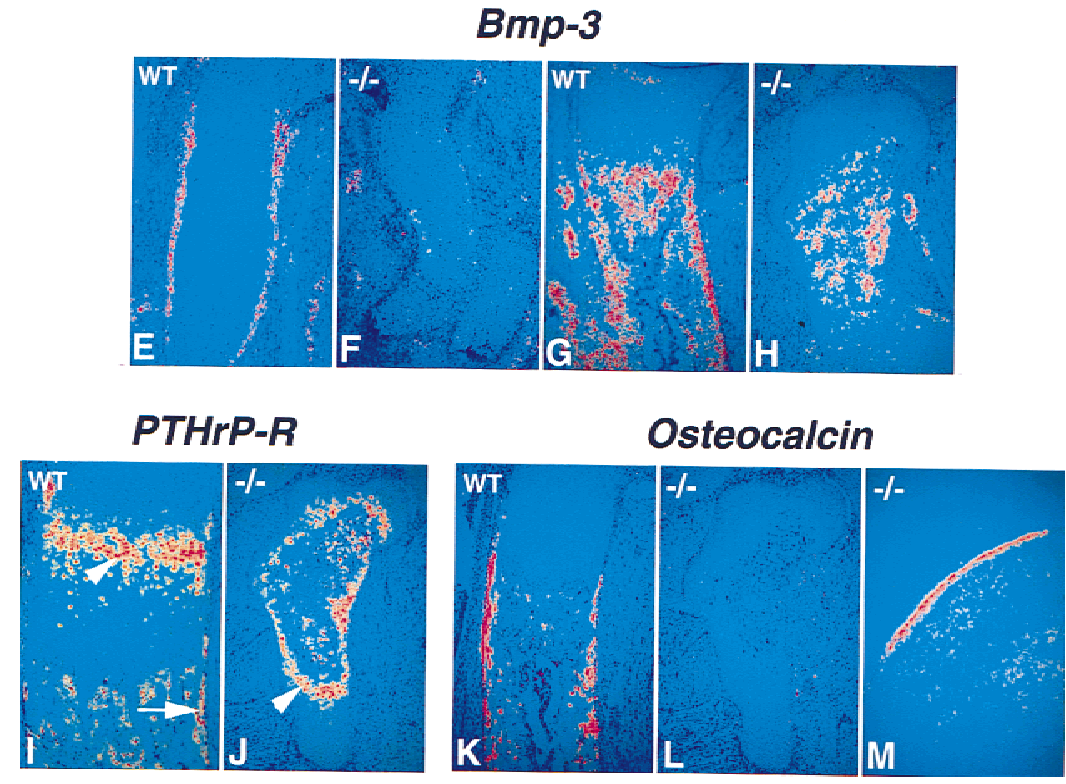

Ihh is a regulator of PTHrP expression and chondrocyte hypertrophy

Previous experiments in chick showed that Ihh controls the transition from proliferating to hypertrophic chondrocyte, most likely by maintaining expression of PTHrP, an inhibitor of chondrocyte maturation (Lanske et al. 1996; Vortkamp et al. 1996). These observations suggested a model that, in its simplest form, predicts that a null mutation in Ihh would lead to down-regulation of PTHrP expression and phenocopy the PTHrP or PTH/PTHrP-R null mutations (Vortkamp et al. 1996). Examination of Ihh mutants indicates that, although this model holds, there are likely to be other PTHrPindependent pathways regulated by Ihh.

Initially chondrocyte maturation is delayed in the long bones but at later stages hypertrophic cells were observed in abnormal positions, close to the ends of the skeletal elements, indicative of the atypical maturation observed in mutants of the PTHrP signaling pathway. As PTHrP expression was absent at the articular surfaces, our data lend genetic support to the model of Vortkamp et al. (1996), which proposed that Ihh produced by newly differentiating postmitotic chondrocytes regulates periarticular PTHrP production positively, thereby putting the brakes on further chondrocyte maturation. Although we have focused on growth and differentiation of the long bones, there are several other features of the Ihh mutant that phenocopy PTHrP and PTH/PTHrP-R mutants. These include ectopic calcification in the cartilaginous synchondroses between the basoccipital and exoccipital bones at the base of the skull, as well as ectopic calcification in the sternum and vertebrae. Thus, an Ihh/ PTHrP regulatory pathway most likely functions in many regions of the developing endochondral skeleton to control chondrocyte differentiation. Whether Ihh acts directly as a long-range signal or by a relay mechanism through a secondary signal to induce/maintain PTHrP expression in the periarticular perichondrium is still unclear. However, the absence of Ptc expression, a general indicator of Hedgehog signaling, in these cells suggests an indirect pathway.

The PTHrP $^{-/-}$phenotype has been interpreted as resulting from an increase in the rate of differentiation of chondrocytes (Lee et al. 1996). This interpretation is based largely on the appearance of the growth plate at 18.5 dpc. Histologically, the PTHrP and PTH/PTHrP-R null mice show a clear reduction in the height of the zone of proliferating chondrocytes with an irregular columnar organization and distortion of the osteochondral junction (Amizuka et al. 1994, 1996; Karaplis et al. 1994; Lanske et al. 1996; Lee et al. 1996). Importantly, it was shown that the rate of chondrocyte proliferation (measured as the percentage of chondrocytes in mitosis in the 
proliferation zone) is not significantly different between wild-type and $\mathrm{PTHr} \mathrm{P}^{-/-}$bones (Lee et al. 1996). Because the rate of proliferation of the chondrocytes is not affected but the number of chondrocytes in the proliferation zone is nonetheless reduced, it was concluded that the rate of differentiation to the hypertrophic phenotype was accelerated leading to depletion of the proliferating population and premature hypertrophy and bone formation (Lee et al. 1996; see also Kronenberg et al. 1997). This interpretation predicts that in mice defective for PTHrP signaling as the proliferative zone shrinks, the hypertrophic zone should expand as more cells enter this terminal state. Conflicting results have been reported. Amizuka et al. (1994) found no difference in the number of hypertrophic chondrocytes in the tibial growth plate of wild-type and $\mathrm{PTHrP}^{-/-}$mice at $18.5 \mathrm{dpc}$, whereas Lee et al. (1996) reported a larger zone of hypertrophic chondrocytes at $15.5 \mathrm{dpc}$ and a wider zone of terminally differentiated chondrocytes at $18.5 \mathrm{dpc}$.

On the basis of published data, we suggest a different interpretation for the role of PTHrP, that PTHrP does not regulate the rate of differentiation of the chondrocytes per se, but only determines the position relative to the articular ends of the developing bone at which chondrocytes exit the cell cycle and initiate the hypertrophic differentiation program. Thus, PTHrP acts as a patterning molecule and the periarticular perichondrium as an 'organizer.' We propose that (1) the periarticular perichondrium is the main source of PTHrP; (2) PTHrP diffuses away from the articular end; (3) high concentrations of PTHrP inhibit hypertrophy, but there is a threshold concentration below which PTHrP no longer prevents initiation of the hypertophic program; and (4) the distance from the articular end at which this threshold concentration is reached depends on the level of transcription of $P T H r P$ in the articular perichondrium. The high levels of $P T H / P T H r P-R$ expressed by the chondrocytes just proximal to the 'prehypertrophic zone' may serve as a sink to prevent diffusion of the PTHrP ligand beyond this point and establish a sharp transition to below-threshold levels of PTHrP as observed for other signaling systems (Perrimon and McMahon 1999). Interestingly, this is where most of the cell-bound PTHrP protein is detected by immunohistochemistry (Amizuka et al. 1994; Lee et al. 1996). In this model, in the absence of PTHrP, chondrocytes initiate differentiation closer to the articular end, after fewer rounds of cellular replication. Although neither the rate of proliferation nor the rate of differentiation of individual cells is altered, the net result is a smaller population of proliferating cells and a smaller "proliferative zone" in the growth plate. Consequently, hypertrophy and ossification are displaced closer to the articular end, as can be seen in both the PTHrP- and Ihh-null mice. In this view, the proliferating population of chondrocytes does not become progressively depleted as development progresses but is displaced spatially toward the articular end. Therefore, excessive ossification is best described as ectopic, not "accelerated." This model is also compatible with the effects of PTHrP overexpression in the mouse (Weir et al.
1996) or ectopic Ihh expression in the chick (Vortkamp et al. 1996), where the concentration of PTHrP may be high enough to inhibit chondrocyte hypertrophy completely.

The observation that formation of hypertrophic chondrocytes is initially delayed in Ihh mutants (the earliest stages of chondrocyte differentiation have not been addressed in PTHrP or PTH/PTHrP-R mutants) appears at odds with the above model. However, if one invokes a regulatory mechanism independent of PTHrP that only permits hypertrophic cell formation when the skeletal element reaches a certain size, the altered growth of the Ihh mutants (see below) may actually delay the initiation of chondrocyte differentiation. Alternatively, Ihh signaling may be involved in actually promoting maturation of the chondrocytes after they escape the regulatory influence of PTHrP, as has been suggested on the basis of observations in cell culture systems (Stott and Chuong 1997; Akiyama et al. 1999).

\section{Ihh is essential for normal chondrocyte proliferation}

The most striking phenotype in the Ihh mutant is a dramatic reduction in the rate of chondrocyte proliferation, resulting in severe dwarfism of axial and appendicular elements. This effect is independent of the maturation process, as it is apparent from as early as $12.5 \mathrm{dpc}$. As neither the PTHrP ${ }^{-/-}$nor the PTH/PTHrP-R ${ }^{-/-}$mice display the severe dwarfism of the $I h h^{-/-}$phenotype (Karaplis et al. 1994; Lanske et al. 1996) or a large reduction in the rate of chondrocyte proliferation per se (Lee et al. 1996), this role of Ihh signaling is independent of PTHrP signaling. Moreover, expression of the general Hedgehog receptor Ptc-1 in proliferating chondrocytes adjacent to Ihh-expressing chondrocytes (this report; see also Vortkamp et al. 1998), and its absence in Ihh mutants is consistent with a direct role for Ihh in stimulating chondrocyte proliferation. Thus, Ihh signaling is most likely involved in the dramatic growth of the endochondral skeleton, which occurs after condensation of skeletal elements. As genetic control of the growth program, in particular by members of the Hox gene family, has been proposed to play a central role in controlling the distinct skeletal morphologies observed in vertebrates (Duboule 1995), it will also be interesting to determine whether Hox genes may act, at least in part, by the control of Ihh signaling.

Hedgehog signaling has been shown to regulate cellular proliferation in several other tissues during vertebrate development. For instance, another member of the Hedgehog family, Sonic hedgehog (Shh) has a proliferative effect on many tissues during mouse development, including the somites (Fan et al. 1995), retina (Jensen and Wallace 1997), skin (Oro et al. 1997; St-Jacques et al. 1998), lung (Bellusci et al. 1997; Pepicelli et al. 1998), skeletal muscles (Duprez et al. 1998), and granule cell precursors in the cerebellum (Wechsler-Reya and Scott 1999|. Finally, Hedgehog signaling also seems capable of promoting a neoplastic state characterized by proliferation of an undifferentiated cell population in at least two 
tumors, basal cell carcinoma (BCC) and medulloblastomas (Gailani et al. 1996; Hahn et al. 1996, 1998; Johnson et al. 1996; Dahmane et al. 1997; Goodrich et al. 1997; Oro et al. 1997; Raffel et al. 1997; Xie et al. 1998). However, at present, it is unclear whether Ihh signaling promotes proliferation of the target cells directly or acts indirectly through the production of a secondary signal.

Recent evidence indicates that Ihh may itself be the target of a second signaling pathway, which regulates cartilage growth negatively. Activating and inactivating mutations in fibroblast growth factor receptor-3 (FGFR3) lead to complementary chondrodysplasias. In human, constitutively active alleles of FGFR-3 cause different forms of autosomal dominant dwarfism (De Moerlooze and Dickson 1997; Webster and Donoghue 1997; Naski and Ornitz 1998). Conversely, in the mouse, null mutations in Fgfr-3 cause skeletal overgrowth (Colvin et al. 1996; Deng et al. 1996). Thus, a normal function of FGFR-3 signaling is to inhibit chondrocyte proliferation in the perinatal growth plate. The skeletons of newborn $I_{h h^{-1-}}$ mice grossly resemble the skeletons of human fetuses suffering from thanatophoric dysplasia (TD). This is the most common form of neonatal-lethal dwarfism in human, and is caused by activating mutations in FGFR-3 (for review, see De Moerlooze and Dickson 1997; Webster and Donoghue 1997; Naski and Ornitz 1998). Interestingly, Naski et al. (1998) have demonstrated that expression of an activated allele of Fgfr-3 leads to a dramatic decrease in the levels of Ihh and Ptc-1 expression postnatally, whereas Ptc-1 expression is up-regulated in Fgfr-3 null mice. Thus, FGFR-3 appears to be an upstream negative regulator of Ihh signaling, but only during postnatal skeletogenesis.

Ihh is required for osteoblast development in endochondral bones

A second PTHrP-independent role for Thh is in bone formation. During embryogenesis, cells adjacent to the mesenchymal condensations elongate and become oriented tangentially to form the perichondrium for stacked-cell layer), which will isolate the chondrocytes from the surrounding mesenchyme (for review, see Caplan and Pechak 1987). Although cells of the outer perichondrium form a fibrous layer, cells of the diaphysal perichondrium closer to the cartilage differentiate into osteoblasts and initiate formation of a bone collar around the cartilage core (for review, see Caplan and Pechak 1987). In the mouse humerus, this process initiates $\sim 13.5 \mathrm{dpc}$ such that by $14.5 \mathrm{dpc}$ the perichondrium is clearly composed of two histologically different layers and deposition of the bone collar is taking place (e.g., see Fig. 5E). In contrast, no bone collar was formed in the Ihh mutant and even at late developmental stages the perichondrium appeared as a loose layer of undifferentiated mesenchymal cells. In the long bones of the Ihh mutant, no cortical or trabecular bone could be detected histologically and there was no detectable osteocalcin expression, indicating the absence of mature osteoblasts. Thus, Ihh signaling is essential for normal osteoblast develop- ment in endochondral bones. Whether Ihh regulates osteoblast differentiation directly or affects bone formation indirectly remains to be determined. Nevertheless, the presence of mature osteoblasts in membranous bones of the Ihh mutant suggests two distinct pathways for osteoblast development and indicates that formation of the bone collar, which is often described as similar to intramembranous ossification, is in fact genetically distinct. Other recent observations also support a role for Hedgehog signaling in osteoblast differentiation. Both Shh and Ihh proteins were shown to stimulate alkaline phosphatase (APase) expression (a marker of osteoblast differentiation) in mesenchymal and osteogenic cell lines in vitro (Kinto et al. 1997; Nakamura et al. 1997), and intramuscular transplantation of chicken fibroblasts expressing Shh into nude mice-induced ectopic bone formation (Kinto et al. 1997). The exact role of Ihh in this process is not clear, but our analysis suggests that during development Ihh signaling is essential for maturation of the perichondrium into an osteogenic tissue from which the very first osteoblasts of the endochondral skeleton will differentiate. Furthermore, the high levels of Ptc-1 expression observed in the perichondrial/periosteal region at the time when osteoblasts precursors form is consistent with a direct role for Ihh signaling. It is unlikely that the absence of osteoblasts is a secondary consequence of a 'developmental delay' in skeletal development in the growth-deficient Ihh mutants. The growth deficiency can be phenocopied by chondrocyte-specific expression of a recently discovered cell-associated regulator of Hedgehog signaling, Hedgehog interacting protein (Hip; Chuang and McMahon 1999), but bone collar formation in the adjacent periosteum, which does not express Hip, is normal (P.-T. Chuang and A.P. McMahon, unpubl.).

The absence of osteoblast differentiation in the $I h h^{-/-}$ perichondrium correlates with an absence of Osf-2/ Cbfa1 expression in this tissue. Osf-2/Cbfa1 encodes a transcriptional regulator of a number of bone-specific target genes (Ducy et al. 1997). Its activity is essential for formation of osteoblasts associated with both intramembranous and endochondral bone formation (Komori et al. 1997; Otto et al. 1997). Interestingly, Osf-2/Cbfa1 expression can be induced by BMPs (Ducy et al. 1997). Bmp-3 (Osteogenin) expression is compatible with a role in maturation of the perichondrium into an osteogenic tissue (our observations, see also Vukicevic et al. 1994; Takahashi and Ikeda 1996; Solloway et al. 1998) and like Osf-2/Cbfa1, Bmp3 expression is absent in this region in Ihh mutants. Whether Ihh regulates Osf-2/Cbfa1 activity directly or indirectly through $B m p 3$, or other $B m p$ family members, remains to be determined.

Osf-2/Cbfa1-mutant mice also show a failure of terminal differentiation of the growth plate chondrocytes (Inada et al. 1999; Kim et al. 1999). This could indicate that terminal differentiation of hypertrophic chondrocytes depends on differentiation of osteoblasts and the formation of a bone collar or it could point to a direct requirement for Osf-2/Cbfa1 expression in maturing chondrocytes. Our observations support a direct role for 
Osf-2/Cbfa1 in chondrocytes, as in the Ihh mutant chondrocytes do undergo terminal differentiation in the complete absence of bone collar formation.

In summary, growth and differentiation of the endochondral skeleton relies on a complex interplay among different signaling factors to regulate the orderly morphogenesis of the skeleton. Among these, Ihh appears to play a central role in coordinating these events.

\section{Materials and methods}

\section{Construction of targeting vector}

Hedgehog cDNAs (Shh and $I h h$ ) were used to screen a mouse $129 /$ SvJ genomic library (gift of Dr. P. Soriano). Two overlapping genomic clones encompassing the Ihh locus were isolated. To construct a positive/negative targeting vector, a $5.0-\mathrm{kb}$ HindIII-EagI fragment containing upstream noncoding sequence was used as a $5^{\prime}$ region of homology and inserted into the ClaI site of the pPGKneo/TK vector (a gift of Dr. T. Gridley) upstream of the PGK-neo-pA cassette. A 5.4-kb HindIII fragment was used as a $3^{\prime}$ region of homology and inserted in the NotI site upstream of the MC1-tk-pA cassette. This fragment contains part of intron 1 and all of exon 2 , intron 2 , and exon 3 . In this targeting construct, exon 1 plus $\sim 1 \mathrm{~kb}$ of flanking sequence are replaced by the neo cassette. The two selectable cassettes are in the same transcriptional orientation as the Ihh gene.

\section{Generation of Ihh null mice}

CJ7 (Swiatek and Gridley 1993) or R1 (Nagy et al. 1993) ES cells were electroporated with SalI-linearized targeting vector and selected in G418 and FIAU $24 \mathrm{hr}$ after electroporation as described (McMahon and Bradley 1990). Drug-resistant colonies were screened by Southern blot analysis of NcoI-digested genomic DNA probed with a KpnI-HindIII fragment located upstream of the $5^{\prime}$ homology region (Fig. 1A). Correct targeting was confirmed by probing an XhoI digest of genomic DNA with a BamHI fragment located downstream of the $3^{\prime}$ region of homology (Fig. 1A). Approximately 1 of 35 drug-resistant ES cell clones had undergone the predicted homologous recombination event at the Ihh locus. Heterozygous ES cells were aggregated with morula stage CD1 embryos or injected into blastocysts of $\mathrm{C} 57 \mathrm{Bl} / 6$ strain mice to generate germ line chimeras. Chimeric males were mated with C57Bl/6, 129/Sv, or Swiss-Webster females and heterozygous offspring were identified by Southern blotting of tail-tip DNA. Heterozygous littermates were mated to obtain embryos homozygous for the Ihh null mutation.

\section{Skeletal preparations, histology, and in situ hybridization}

Yolk sac-derived genomic DNA was genotyped by either Southern blotting with indicated probes or PCR. Primers specific for the wild-type and mutant alleles were used in separate PCR reactions. Reactions were performed in a buffer containing 50 $\mathrm{mm} \mathrm{KCl}, 10 \mathrm{~mm}$ Tris- $\mathrm{HCl}(\mathrm{pH} 8.4), 1.5 \mathrm{~mm} \mathrm{MgCl}_{2}$, and $20 \mu \mathrm{g} / \mathrm{ml}$ gelatin. For the wild-type allele, the primers Ihh-5' (5'-AGGAGGCAGGGACATGGATA GGGTG-3') and $I h h$-exon 1 (5'-AGGAACAGACACAGAACCGCAGTCGGG-3') generated a 600bp fragment. The reaction conditions were $1 \mathrm{~min}$ at $94^{\circ} \mathrm{C}, 1 \mathrm{~min}$ at $66^{\circ} \mathrm{C}$, and $1 \mathrm{~min}$ at $72^{\circ} \mathrm{C}$ for 35 cycles using deazaGTP. For the targeted allele, the primers Ihh-5' and PGK-neo (5'-TACCGGTGGATGTGGAATGTGT GCG-3') generated a 307-bp frag- ment. The condition reactions were $1 \mathrm{~min}$ at $94^{\circ} \mathrm{C}, 1 \mathrm{~min}$ at $62^{\circ} \mathrm{C}$, and $1 \mathrm{~min}$ at $72^{\circ} \mathrm{C}$ for 40 cycles.

For skeletal preparations, 14.5- to 18.5-dpc embryos and newborn mice were eviscerated and fixed in $95 \%$ ethanol overnight and processed as described (Parr and McMahon 1995). Skeletal preparations of earlier developmental stages were performed as described by Jegalian and DeRobertis (1992) except that staining was overnight. For histological analysis, embryos were fixed overnight in Bouin's fixative at room temperature, rinsed extensively in $70 \%$ ethanol, dehydrated through an ethanol series, cleared in xylene, embedded in paraffin, and sectioned at $6 \mu \mathrm{m}$. Staining was with hematoxylin and eosin. For in situ hybridization and BrdU detection, embryos were fixed overnight at $4^{\circ} \mathrm{C}$ in $4 \%$ paraformaldehyde/PBS, rinsed in saline, and processed as above. Section in situ hybridization using ${ }^{35}$ S-labeled riboprobes was performed as described (Wilkinson 1992). Riboprobes were as described previously: Ihh (Bitgood and McMahon 1995), Ptc-1 (Goodrich et al. 1996), Gli (Hui et al. 1994), Osf-2/ CbfA1 (Ducy et al. 1997), osteocalcin (Desbois et al. 1994),

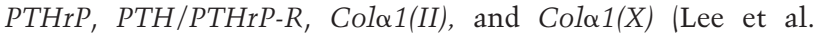
1996). The Bmp3 probe was a gift from Dr. Brigid Hogan.

\section{Analysis of BrdU incorporation}

Pregnant mice were injected intraperitoneally with $50 \mu \mathrm{g} \mathrm{BrdU/}$ gram body weight $1 \mathrm{hr}$ before sacrifice. Embryos were treated as above, forelimbs were dissected and embedded to obtain longitudinal sections through the humerus. BrdU was detected by immunohistochemistry essentially as described (Nowakowski et al. 1989), and sections were counterstained lightly with toluidine blue. The proliferative zone of the growth plate was defined as the area from the distal end of the humerus to the last labeled chondrocyte nucleus near the hypertrophic zone. All BrdU-positive (black) and -negative (blue) nuclei in this zone were counted. At least five different sections were counted for each of two wild-type and two $\mathrm{Ihh}^{-/-}$littermate embryos at each developmental stage.

\section{Acknowledgments}

We thank all those who supplied probes, Bianca Klumpar for histology, Jill McMahon for ES cell injection, and Drs. Cliff Tabin, Henry Kronenberg, Gino Segre, and Seth Karp for stimulating discussion. Work in A.P.M.'s laboratory was supported by grants from the National Institutes of Health. B.St-J. and M.H. were supported by fellowships from the Medical Research Council of Canada and Human Frontier Science Program, respectively.

The publication costs of this article were defrayed in part by payment of page charges. This article must therefore be hereby marked 'advertisement' in accordance with 18 USC section 1734 solely to indicate this fact.

\section{References}

Akiyama, H., C. Shigeno, K. Iyama, H. Ito, Y. Hiraki, J. Konoshi, and T. Nakamura. 1999. Indian hedgehog in the late-phase differentiation in mouse chondrogenic EC cells, ATDC5: Upregulation of type X collagen and osteoprotegerin ligand mRNAs. Biochem. Biophys. Res. Commun. 257: 814-820.

Amizuka, N., H. Warshawsky, J. E. Henderson, D. Goltzman, and A. C. Karaplis. 1994. Parathyroid hormone-related peptide-depleted mice show abnormal epiphyseal cartilage development and altered endochondral bone formation. J. Cell. Biol. 126: 1611-1623. 
Amizuka, N., J. E. Henderson, K. Hoshi, H. Warshawsky, H. Ozawa, D. Goltzman, and A.C. Karaplis. 1996. Programmed cell death of chondrocytes and aberrant chondrogenesis in mice homozygous for parathyroid hormone-related peptide gene deletion. Endocrinology 137: 5055-5067.

Apte, S.S., M.F. Seldin, M. Hayashi, and B.R. Olsen. 1992. Cloning of the human and mouse type $\mathrm{X}$ collagen genes and mapping of the mouse type $\mathrm{X}$ collagen gene to chromosome 10 . Eur. J. Biochem. 206: 217-224.

Aubin, J. and F. Liu. 1996. The osteoblast lineage. In Principles of bone biology (ed. J.P. Bilezikian, L.G. Raisz, and G.A. Rodan), pp. 51-67. Academic Press, New York, NY.

Becker, S., Z.J. Wang, H. Massey, A. Arauz, P. Labosky, M. Hammerschmidt, B. St-Jacques, D. Bumcrot, A. McMahon, and L. Grabel. 1997. A role for Indian hedgehog in extraembryonic endoderm differentiation in F9 cells and the early mouse embryo. Dev. Biol. 187: 298-310.

Bellusci, S., Y. Furuta, M.G. Rush, R. Henderson, G. Winnier, and B.L. Hogan. 1997. Involvement of Sonic hedgehog (Shh) in mouse embryonic lung growth and morphogenesis. Development 124: 53-63.

Bitgood, M.J. and A.P. McMahon. 1995. Hedgehog and Bmp genes are coexpressed at many diverse sites of cell-cell interaction in the mouse embryo. Dev. Biol. 172: 126-138.

Caplan, A.I. and D.G. Pechak. 1987. The cellular and molecular embryology of bone formation. In Bone and mineral research. Vol. 5. (ed. W.A. Peck), pp. 117-183. Elsevier, New York, NY.

Chuang, P.-T. and A.P. McMahon. 1999. Modulation of Hedgehog signaling through the induction of a Hedgehog-interacting protein, Hip. Nature 397: 617-621.

Chung, U.I., B. Lanske, K. Lee, E. Li, and H. Kronenberg. 1998. The parathyroid hormone/parathyroid hormone-related peptide receptor coordinates endochondral bone development by directly controlling chondrocyte differentiation. Proc. Nat1. Acad. Sci. 95: 13030-13035.

Colvin, J.S., B.A. Bohne, G.W. Harding, D.G. McEwen, and D.M. Ornitz. 1996. Skeletal overgrowth and deafness in mice lacking fibroblast growth factor receptor 3. Nature Genet. 12: 390-397.

Dahmane, N., J. Lee, P. Robins, P. Heller, and A. Ruiz i Altaba. 1997. Activation of the transcription factor Glil and the Sonic hedgehog signalling pathway in skin tumours. Nature 389: 876-881.

De Moerlooze, L. and C. Dickson. 1997. Skeletal disorders associated with fibroblast growth factor receptor mutations. Curr. Opin. Genet. Dev. 7: 378-385.

Deng, C., A. Wynshaw-Boris, F. Zhou, A. Kuo, and P. Leder. 1996. Fibroblast growth factor receptor 3 is a negative regulator of bone growth. Cell 84: 911-921.

Desbois, C., D.A. Hogue, and G. Karsenty. 1994. The mouse osteocalcin gene cluster contains three genes with two separate spatial and temporal patterns of expression. J. Biol. Chem. 269: 1183-1190.

Duboule, D. 1995. Vertebrate Hox genes and proliferation: An alternative pathway to homeosis? Curr. Opin. Genet. Dev. 5: $525-528$.

Ducy, P., R. Zhang, V. Geoffroy, A.L. Ridall, and G. Karsenty. 1997. Osf2/Cbfa1: A transcriptional activator of osteoblast differentiation. Cell 89: 747-754.

Duprez, D., C. Fournier-Thibault, and N. Le Douarin. 1998. Sonic Hedgehog induces proliferation of committed skeletal muscle cells in the chick limb. Development 125: 495-505.

Elima, K., I. Eerola, R. Rosati, M. Metsaranta, S. Garofalo, M. Perala, B. De Crombrugghe, and E. Vuorio. 1993. The mouse collagen X gene: Complete nucleotide sequence, exon struc- ture and expression pattern. Biochem. J. 289: 247-253.

Erlebacher, A., E.H. Filvaroff, S.E. Gitelman, and R. Derynck. 1995. Toward a molecular understanding of skeletal development. Cell 80: 371-378.

Fan, C.M., J.A. Porter, C. Chiang, D.T. Chang, P.A. Beachy, and M. Tessier-Lavigne. 1995. Long-range sclerotome induction by sonic hedgehog: Direct role of the amino-terminal cleavage product and modulation by the cyclic AMP signaling pathway. Cell 81: 457-465.

Farrington, S.M., M. Belaoussoff, and M.H. Baron. 1997. Winged-helix, Hedgehog and Bmp genes are differentially expressed in distinct cell layers of the murine yolk sac. Mech. Dev. 62: 197-211.

Gailani, M.R., M. Stahle-Backdahl, D.J. Leffell, M. Glynn, P.G. Zaphiropoulos, C. Pressman, A.B. Unden, M. Dean, D.E. Brash, A.E. Bale, and R. Toftgard. 1996. The role of the human homologue of Drosophila patched in sporadic basal cell carcinomas. Nature Genet. 14: 78-81.

Gilbert, S.F. 1997. Developmental biology. Sinauer Associates, Inc., Sunderland, MA

Goodrich, L.V., R.L. Johnson, L. Milenkovic, J.A. McMahon, and M.P. Scott. 1996. Conservation of the hedgehog/patched signaling pathway from flies to mice: Induction of a mouse patched gene by Hedgehog. Genes \& Dev. 10:301-312.

Goodrich, L.V., L. Milenkovic, K.M. Higgins, and M.P. Scott. 1997. Altered neural cell fates and medulloblastoma in mouse patched mutants. Science 277: 1109-1113.

Hahn, H., C. Wicking, P.G. Zaphiropoulous, M.R. Gailani, S. Shanley, A. Chidambaram, I. Vorechovsky, E. Holmberg, A.B. Unden, S. Gillies, K. Negus, I. Smyth, C. Pressman, D.J. Leffell, B. Gerrard, A.M. Goldstein, M. Dean, R. Toftgard, G. Chenevix-Trench, B. Wainwright, and A.E. Bale. 1996. Mutations of the human homolog of Drosophila patched in the nevoid basal cell carcinoma syndrome. Cell 85: 841-851.

Hahn, H., L. Wojnowski, A.M. Zimmer, J. Hall, G. Miller, and A. Zimmer. 1998. Rhabdomyosarcomas and radiation hypersensitivity in a mouse model of Gorlin syndrome. Nature Med. 4: 619-622.

Hall, B.K. 1988. The embryonic development of bone. Am. Sci. 76: $174-181$

Hinchcliffe, J.R. and D.R. Johnson. 1990. The development of the vertebrate limb. Clarendon Press, Oxford, UK.

Horton, W.A. 1990. The biology of bone growth. Growth. Genet. Horm. 6: 1-3.

Hui, C.C., D. Slusarski, K.A. Platt, R. Holmgren, and A.L. Joyner. 1994. Expression of three mouse homologs of the Drosophila segment polarity gene cubitus interruptus, Gli, Gli2 , and Gli-3, in ectoderm- and mesoderm-derived tissues suggests multiple roles during postimplantation development. Dev. Biol. 162: 402-413.

Inada, M., T. Yasui, S. Nomura, S. Miyake, K. Deguchi, M. Himeno, M. Sato, H. Yamagiwa, T. Kimura, N. Yasui T. Ochi, N. Endo, Y. Kishimoto, and T. Komori. 1999. Maturational disturbance of chondrocytes in Cbfa1-deficient mice. Dev. Dyn. 214: :279-290.

Ingham, P.W. 1998. Transducing Hedgehog: The story so far. EMBO J. 17: 3505-3511.

Iwasaki, M., A.X. Le, and J.A. Helms. 1997. Expression of indian hedgehog, bone morphogenetic protein 6 and gli during skeletal morphogenesis. Mech. Dev. 69: 197-202.

Jegalian, B.G. and E.M. De Robertis. 1992. Homeotic transformations in the mouse induced by overexpression of a human Hox3.3 transgene. Cell 71: 901-910.

Jensen, A.M. and V.A. Wallace. 1997. Expression of Sonic hedgehog and its putative role as a precursor cell mitogen in the developing mouse retina. Development 124: 363-371. 
Johnson, R.L., A.L. Rothman, J. Xie, L.V. Goodrich, J.W. Bare, J.M. Bonifas, A.G. Quinn, R.M. Myers, D.R. Cox, E.H. Epstein Jr., and M.P. Scott. 1996. Human homolog of patched, a candidate gene for the basal cell nevus syndrome. Science 272: $1668-1671$.

Karaplis, A.C., A. Luz, J. Glowacki, R.T. Bronson, V.L. Tybulewicz, H.M. Kronenberg, and R.C. Mulligan. 1994. Lethal skeletal dysplasia from targeted disruption of the parathyroid hormone-related peptide gene. Genes \& Dev. 8: 277289.

Kim, I.S., F. Otto, B. Zabel, and S. Mundlos. 1999. Regulation of chondrocyte differentiation by cbfa1. Mech. Dev. 80: 159170.

Kinto, N., M. Iwamoto, M. Enomoto-Iwamoto, S. Noji, H. Ohuchi, H. Yoshioka, H. Kataoka, Y. Wada, G. Yuhao, H.E. Takahashi, S. Yoshiki, and A. Yamaguchi. 1997. Fibroblasts expressing Sonic hedgehog induce osteoblast differentiation and ectopic bone formation. FEBS Lett. 404: 319-323.

Komori, T., H. Yagi, S. Nomura, A. Yamaguchi, K. Sasaki, K. Deguchi, Y. Shimizu, R.T. Bronson, Y.H. Gao, M. Inada, M. Sato, R. Okamoto, Y. Kitamura, S. Yoshiki, and T. Kishimoto. 1997. Targeted disruption of Cbfal results in a complete lack of bone formation owing to maturational arrest of osteoblasts. Cell 89: 755-764.

Kronenberg, H.M., K. Lee, B. Lanske, and G. V. Segre. 1997. Parathyroid hormone-related protein and Indian hedgehog control the pace of cartilage differentiation. J. Endocrinol. (Suppl.) 154: S39-45.

Lanske, B., A.C. Karaplis, K. Lee, A. Luz, A. Vortkamp, A. Pirro, M. Karperien, L.H. K. Defize, C. Ho, R.C. Mulligan, A.B. Abou-Samra, H. Juppner, G.V. Segre, and H.M. Kronenberg. 1996. PTH/PTHrP receptor in early development and Indian hedgehog-regulated bone growth. Science 273: 663-666.

Lee, K., J.D. Deeds, S. Chiba, M. Un-No, A.T. Bond, and G.V. Segre. 1994. Parathyroid hormone induces sequential c-fos expression in bone cells in vivo: In situ localization of its receptor and c-fos messenger ribonucleic acids. Endocrinology 134: 441-450.

Lee, K., J.D. Deeds, and G.V. Segre. 1995. Expression of parathyroid hormone-related peptide and its receptor messenger ribonucleic acids during fetal development of rats. Endocrinology 136: 453-463.

Lee, K., B. Lanske, A.C. Karaplis, J.D. Deeds, H. Kohno, R.A. Nissenson, H.M. Kronenberg, and G.V. Segre. 1996. Parathyroid hormone-related peptide delays terminal differentiation of chondrocytes during endochondral bone development. Endocrinology 137: 5109-5118.

Linsenmayer, T.F., Q.A. Chen, E. Gibney, M.K. Gordon, J.K. Marchant, R. Mayne, and T.M. Schmidt. 1991. Collagen type IX and $\mathrm{X}$ in the developing chick tibiotarsus: Analyses of mRNA and proteins. Development 111: 191-196.

McMahon, A.P. and A. Bradley. 1990. The Wnt-1 proto-oncogene is required for development of a large region of the mouse brain. Cell 62: 1073-1085.

Nagy, A., J. Rossant, R. Nagy, W. Abramow-Newerly, and J.C. Roder. 1993. Derivation of completely cell culture-derived mice from early-passage embryonic stem cells. Proc. Nat1. Acad. Sci. 90: 8424-8428.

Nakamura, T., T. Aikawa, M. Iwamoto-Enomoto, M. Iwamoto, Y. Higuchi, M. Pacifici, N. Kinto, A. Yamaguchi, S. Noji, K. Kurisu, T. Matsuya, and P. Maurizio. 1997. Induction of osteogenic differentiation by hedgehog proteins. Biochem. Biophys. Res. Commun. 237: 465-469.

Naski, M.C. and D.M. Ornitz. 1998. FGF signaling in skeletal. Front. Biosci. 3: D781-794.

Naski, M.C., J.S. Colvin, J.D. Coffin, and D.M. Ornitz. 1998.
Repression of hedgehog signaling and BMP4 expression in growth plate cartilage by fibroblast growth factor receptor 3 . Development 125: 4977-4988.

Nowakowski, R.S., S.B. Lewin, and M.W. Miller. 1989. Bromodeoxyuridine immunohistochemical determination of the lengths of the cell cycle and the DNA-synthetic phase for an anatomically defined population. J. Neurocytol. 18: 311318.

Oro, A.E., K.M. Higgins, Z. Hu, J.M. Bonifas, E.H. Epstein Jr., and M.P. Scott. 1997. Basal cell carcinomas in mice overexpressing sonic hedgehog. Science 276: 817-821.

Otto, F., A.P. Thornell, T. Crompton, A. Denzel, K.C. Gilmour, I.R. Rosewell, G.W. Stamp, R.S. Beddington, S. Mundlos, B.R. Olsen, P.B. Selby, and M.J. Owen. 1997. Cbfal, a candidate gene for cleidocranial dysplasia syndrome, is essential for osteoblast differentiation and bone development. Cell 89: $765-771$

Parr, B.A. and A.P. McMahon. 1995. Dorsalizing signal Wnt-7a required for normal polarity of D-V and A-P axes of mouse limb. Nature 374: 350-353.

Perrimon, N. and A.P. McMahon. 1999. Negative feedback loops and their roles during pattern formation. Cell 97: 1316.

Pepicelli, C.V., P.M. Lewis, and A.P. McMahon. 1998. Sonic hedgehog regulates branching morphogenesis in the mammalian lung. Curr. Biol. 8: 1083-1086.

Poole, A.R. 1991. The growth plate: Cellular physiology, cartilage assembly and mineralization. In Cartilage: Molecular aspects (ed. B.K. Hall, and S.A. Newman), pp. 179-211. CRC Press, Boca Raton, FL.

Raffel, C., R.B. Jenkins, L. Frederick, D. Hebrink, B. Alderete, D.W. Fults, and C.D. James. 1997. Sporadic medulloblastomas contain PTCH mutations. Cancer Res. 57: 842-845.

Recker, R.R. 1992. Embryology, anatomy and microstructure of bone. In Disorders of bone and mineral metabolism (ed. F.L. Coe and M.J. Favus), pp. 219-240. Raven Press, New York, NY.

Reddi, A.H. 1994. Bone and cartilage differentiation. Curr. Opin. Genet. Dev. 4: 737-744.

Rodan, G.A. and S. Harada. 1997. The missing bone. Cell 89: 677-680.

Schipani, E., K. Kruse, and H. Juppner. 1995. A constitutively active mutant PTH-PTHrP receptor in Jansen-type metaphyseal chondrodysplasia. Science 268: 98-100.

Schipani, E., C.B. Langman, A.M. Parfitt, G.S. Jensen, S. Kikuchi, S.W. Kooh, W.G. Cole, and H. Juppner. 1996. Constitutively activated receptors for parathyroid hormone and parathyroid hormone-related peptide in Jansen's metaphyseal chondrodysplasia. N. Engl. J. Med. 335: 708-714.

Schipani, E., B. Lanske, J. Hunzelman, A. Luz, C.S. Kovacs, K. Lee, A. Pirro, H.M. Kronenberg, and H. Juppner. 1997. Targeted expression of constitutively active receptors for parathyroid hormone and parathyroid hormone-related peptide delays endochondral bone formation and rescues mice that lack parathyroid hormone-related peptide. Proc. Natl. Acad. Sci. 94: 13689-13694.

Solloway, M.J., A.T. Dudley, E.K. Bikoff, K.M. Lyons, B.L. Hogan, and E.J. Robertson. 1998. Mice lacking Bmp6 function. Dev. Genet. 22: 321-339.

St-Jacques, B., H.R. Dassule, I. Karavanova, V.A. Botchkarev, J. Li, P.S. Danielian, J.A. McMahon, P.M. Lewis, R. Paus, and A.P. McMahon. 1998. Sonic hedgehog signaling is essential for hair development. Curr. Biol. 8: 1058-1068.

Stott, N.S. and C.M. Chuong. 1997. Dual action of sonic hedgehog on chondrocyte hypertrophy: Retrovirus mediated ectopic sonic hedgehog expression in limb bud micromass cul- 
ture induces novel cartilage nodules that are positive for alkaline phosphatase and type $\mathrm{X}$ collagen. I. Cell. Sci. 110: 2691-2701.

Swiatek, P.J. and T. Gridley. 1993. Perinatal lethality and defects in hindbrain development in mice homozygous for a targeted mutation of the zinc finger gene Krox20. Genes \& Dev. 7: 2071-2084.

Takahashi, H. and T. Ikeda. 1996. Transcripts for two members of the transforming growth factor-beta superfamily BMP-3 and BMP-7 are expressed in developing rat embryos. Dev. Dyn. 207: 439-449.

Vortkamp, A., K. Lee, B. Lanske, G.V. Segre, H.M. Kronenberg, and C.J. Tabin. 1996. Regulation of rate of cartilage differentiation by Indian hedgehog and PTH-related protein. Science 273: 613-622.

Vortkamp, A., S. Pathi, G.M. Peretti, E.M. Caruso, D.J. Zaleske, and C.J. Tabin. 1998. Recapitulation of signals regulating embryonic bone formation during postnatal growth and in fracture repair. Mech. Dev. 71: 65-76.

Vukicevic, S., M.N. Helder, and F.P. Luyten. 1994. Developing human lung and kidney are major sites for synthesis of bone morphogenetic protein-3 (osteogenin). I. Histochem. Cytochem. 42: 869-875.

Wallis, G.A. 1996. Bone growth: Coordinating chondrocyte differentiation. Curr. Biol. 6: 1577-1580.

Webster, M.K. and D.J. Donoghue. 1997. FGFR activation in skeletal disorders: Too much of a good thing. Trends Genet. 13: $178-182$.

Wechsler-Reya, R.J. and M.P. Scott. 1999. Control of neuronal precursor proliferation in the cerebellum by Sonic hedgehog. Neuron 22: 103-114.

Wilkinson, D.G. 1992. Whole mount in situ hybridization to vertebrate embryos. In In situ hybridization: A practical approach (ed. D.G. Wilkinson), pp. 75-83. IRL Press, Oxford, UK.

Weir, E.C., W.M. Philbrick, M. Amling, L.A. Neff, R. Baron, and A.E. Broadus. 1996. Targeted overexpression of parathyroid hormone-related peptide in chondrocytes causes chondrodysplasia and delayed endochondral bone formation. Proc. Nat1. Acad. Sci. 93: 10240-10245.

Xie, J., M. Murone, S.M. Luoh, A. Ryan, Q. Gu, C. Zhang, J.M. Bonifas, C.W. Lam, M. Hynes, A. Goddard, A. Rosenthal, E.H. Epstein Jr., and F.J. de Sauvage. 1998. Activating Smoothened mutations in sporadic basal-cell carcinoma. Nature 391: 90-92.

Zou, H., R. Wieser, J. Massague, and L. Niswander. 1997. Distinct roles of type I bone morphogenetic protein receptors in the formation and differentiation of cartilage. Genes \& Dev. 11: 2191-2203. 


\section{Erratum}

Genes \& Development 13: 2072-2086 (1999)

Indian hedgehog signaling regulates proliferation and differentiation of chondrocytes and is essential for bone formation

Benoit St-Jacques, Matthias Hammerschmidt, and Andrew P. McMahon

The sequence of the primer for the wild-type allele Ihh-exon 1 was written incorrectly in the Materials and Methods section of the above paper. The correct sequence should read as follows:

5'-AGGAACAGACAGAACCGCAGTCGGG-3' indicating 25 nucleotides.

The authors apologize for any inconvenience. 


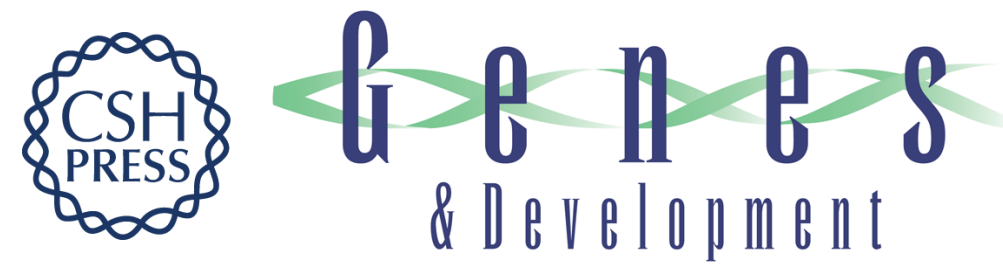

\section{Indian hedgehog signaling regulates proliferation and differentiation of chondrocytes and is essential for bone formation}

Benoit St-Jacques, Matthias Hammerschmidt and Andrew P. McMahon

Genes Dev. 1999, 13:

Related Content Errata for vol. 13, p. 2072

Genes Dev. October , 1999 13: 2617

References This article cites 72 articles, 24 of which can be accessed free at: http://genesdev.cshlp.org/content/13/16/2072.full.html\#ref-list-1

Articles cited in:

http://genesdev.cshlp.org/content/13/16/2072.full.html\#related-urls

License

Email Alerting Receive free email alerts when new articles cite this article - sign up in the box at the top

Service right corner of the article or click here.

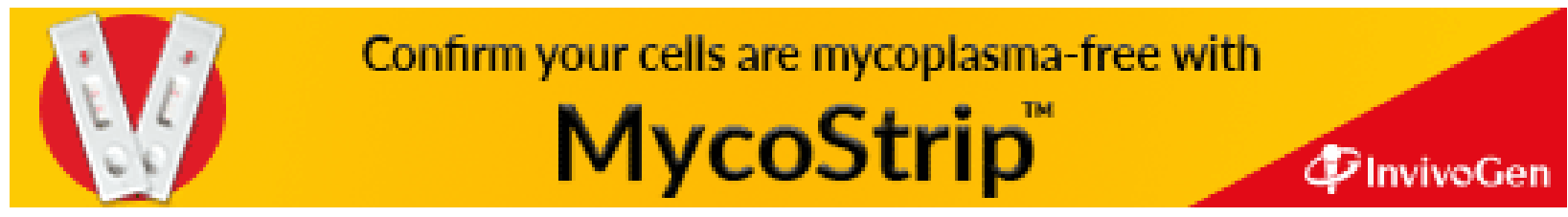

